\title{
A Review of Additive Mixed-Electric Discharge Machining: Current Status and Future Perspectives for Surface Modification of Biomedical Implants
}

\author{
Abdul'Azeez Abdu Aliyu, 1,2 Ahmad Majdi Abdul-Rani, ${ }^{1,2}$ Turnad Lenggo Ginta, ${ }^{2}$ \\ Chander Prakash, ${ }^{3}$ Eugen Axinte, ${ }^{4}$ Muhammad Alhapis Razak, ${ }^{5}$ and Sadaqat Ali $^{2}$ \\ ${ }^{1}$ Centre for Intelligent Signal and Imaging Research, Universiti Teknologi PETRONAS, Bandar Seri Iskandar, Perak, Malaysia \\ ${ }^{2}$ Mechanical Engineering Department, University Technology PETRONAS, Bandar Seri Iskandar, Perak, Malaysia \\ ${ }^{3}$ School of Mechanical Engineering, Lovely Professional University, Phagwara, Punjab 144411, India \\ ${ }^{4}$ Faculty of Machine Manufacturing \& Industrial Management, Gheorghe Asachi Technical University of Iaşi, \\ 59 A Prof. Dimitrie, Iaşi, Romania \\ ${ }^{5}$ Manufacturing Section, Universiti Kuala Lumpur Malaysian Spanish Institute, Kulim Hi-Tech Park, 09000 Kedah, Malaysia \\ Correspondence should be addressed to Ahmad Majdi Abdul-Rani; majdi@utp.edu.my
}

Received 23 April 2017; Accepted 1 August 2017; Published 13 September 2017

Academic Editor: Patrice Berthod

Copyright (C) 2017 Abdul'Azeez Abdu Aliyu et al. This is an open access article distributed under the Creative Commons Attribution License, which permits unrestricted use, distribution, and reproduction in any medium, provided the original work is properly cited.

Surface treatment remained a key solution to numerous problems of synthetic hard tissues. The basic methods of implant surface modification include various physical and chemical deposition techniques. However, most of these techniques have several drawbacks such as excessive cost and surface cracks and require very high sintering temperature. Additive mixed-electric discharge machining (AM-EDM) is an emerging technology which simultaneously acts as a machining and surface modification technique. Aside from the mere molds, dies, and tool fabrication, AM-EDM is materializing to finishing of automobiles and aerospace, nuclear, and biomedical components, through the concept of material migrations. The mechanism of material transfer by AMEDM resembles electrophoretic deposition, whereby the additives in the AM-EDM dielectric fluids are melted and migrate to the machined surface, forming a mirror-like finishing characterized by extremely hard, nanostructured, and nanoporous layers. These layers promote the bone in-growth and strengthen the cell adhesion. Implant shaping and surface treatment through AM-EDM are becoming a key research focus in recent years. This paper reports and summarizes the current advancement of AM-EDM as a potential tool for orthopedic and dental implant fabrication. Towards the end of this paper, the current challenges and future research trends are highlighted.

\section{Introduction}

Electrical discharge machining (EDM) is an advanced machining process used to shape any electrically conductive material. It serves as an alternative to traditional processes such as milling, drilling, and polishing [1]. EDM has proven to have an outstanding performance in machining advanced materials and in producing highly complex shapes [26]. Thus, it recently draws the attention of quite several researchers and industries. The use of EDM in mold, tools, automobiles, and aerospace industries has been largely documented [7, 8]. However, Volosova et al. [9] report the usage of EDM to produce thin-walled separators in the nuclear industry. A new technological innovation which involves mixing the dielectric fluids with certain additives such as metal powders, surfactant, nitrogen, and oxygen gasses has broadened the EDM applications. Thus, when the powder particles are added to the dielectric fluid, the machining technique is called powder mixed-EDM (PM-EDM) or is generally referred to as additive mixed-EDM (AM-EDM). Recently, the application of AM-EDM in the biomedical field has drawn a commendable attention [10-12]. Apart from enhancing the corrosion and wear resistance, AM-EDM has immensely contributed to improving the fatigue life and 


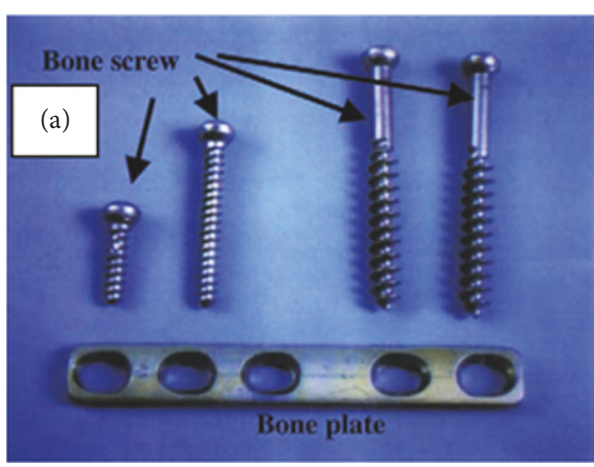

(a)

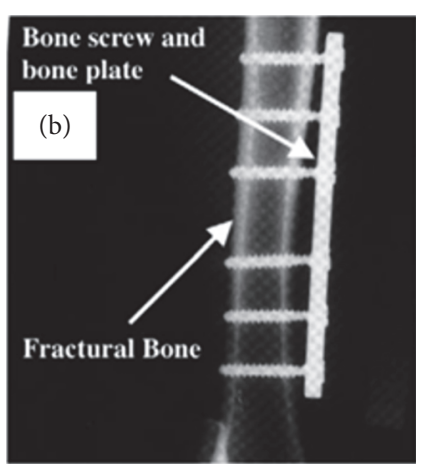

(b)

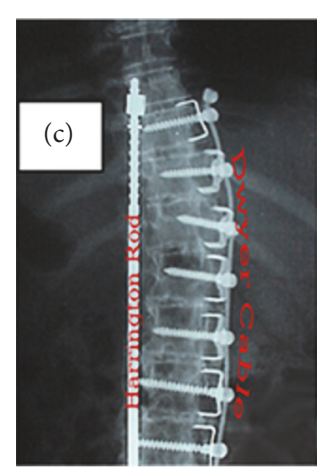

(c)

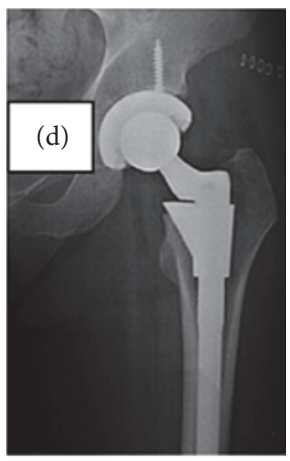

(d)

FIGURE 1: (a) Bone plate screws. (b) Implanted bone plate and screws. (c) The Harrington rod. (d) The stem of the total hip replacement (SS, Co-based, or Ti-based alloys) [41, 42].

mechanical properties of the orthopedic implants [13-18]. However, the use of AM-EDM to deposit a nanoporous and biocompatible layer on the machined implant surface has been lately reported $[19,20]$. This deposited layer provides a strong implant-bone bonding.

The routinely used orthopedic and dental materials are stainless steel, Co-Cr alloys, Mg alloys, and Ti alloys. These materials are normally shaped in the form of wires, rods, pins, screws, and plates (Figure 1) depending on the application site. A good biomaterial should have enough biocompatibility, sufficient strength, good wear, and corrosion resistance as well as bone-matched modulus of elasticity [21]. Stainless steel is easily affordable and has appreciable manufacturability, but its low strength, high modulus of elasticity, and release of toxic elements after implantation limit its application. Despite the fact that Co-based alloys have proved to be superior to stainless steel in terms of strength and corrosion resistance, its manufacturing cost is too high. Tibased alloys are reported to be the most suitable in the field of biomedical research when compared with stainless steel and Co-based alloys, owing to their reasonable biocompatibility, good corrosion resistance, lower modulus of elasticity, and high specific strength [22]. The main drawbacks of Ti-based alloys include their high cost, severe wear, and insufficient osteointegration [23]. Among biodegradable alloys, Mg alloys were reported to have higher biocompatibility and bonesuited mechanical properties. However, their faster degradation before the maturity of the repaired bone crippled their biomedical applications [24-27]. Several efforts to produce safer and higher quality biomaterials that closely match the bone properties have been introduced. Thus, the discovery of bioglass emerged around the 1970s. Unfortunately, this material developed unsatisfied mechanical properties, especially when applied in load-bearing areas [28]. In the 1960s, metallic glasses (MGs) were discovered and revealed to possess sufficient strength and superior corrosion resistance when compared to Ti alloys [29]. However, the drawback of MGs is their limited specimen size (usually in micron) which retards their application in research and biomedical field [30]. In recent years, higher glass formers elements such as $\mathrm{Pd}, \mathrm{Ni}, \mathrm{Be}$, and $\mathrm{Al}$ were discovered. This led to the development and production of MGs into larger size (up to $10 \mathrm{~mm}$ diameter and $100 \mathrm{~mm}$ long) called Bulk Metallic Glasses (BMGs) [31]. It is believed that BMGs maintained the corrosion and wear behavior of the MGs as revealed by Ge et al. [32]. Biodegradable and nonbiodegradable BMGs can be fabricated depending on the alloy combination. The fabrication method of BMGs is like that of plastics. They are commercially processed mainly by injection molding or die casting.

Despite the continuous emergence of new biomedical materials, there are still unsolved issues such as poor bioactivity, high elastic modulus, and release of toxic elements after implantation. To solve these problems, several authors considered depositing a biocompatible, bioactive, and nonporous layer on the implant surface through several kind methods [33]. Calcium phosphate (CaP) compounds, such as hydroxyapatite (HA) which contains the main inorganic component of the bone, were adopted as coating material by many researchers. It was revealed that $\mathrm{CaP} / \mathrm{HA}$ surface coating not only increases the biocompatibility but also provides a very tight implant-tissue bonding $[34,35]$. In addition, porous material is believed to have a reasonable and an adjustable modulus of elasticity [36].

The outstanding performance of AM-EDM, especially with regard to material migration and deposition, has recently drawn the attention of many researchers. Several authors have attempted to investigate the potential of AMEDM to machine biomedical implants and devices. Klocke et al. [37] reported that EDM can efficiently shape $\mathrm{Mg}$ alloys. However, a good finishing without compromise of the material's crystal arrangement or initial performance was achieved. Addition of graphite powder and the surfactant to the dielectric fluid greatly reduced the thickness of the formed recast layer, thereby enhancing the biomedical performance of Ti-6Al-4V [38]. A reasonable transfer of material between the dielectric additives, electrodes materials, was observed during AM-EDM of die steels [39, 40].

This paper critically reviewed the technological advancements of EDM and the current perspective of AM-EDM as a surface modification technique for orthopedic and dental applications. The paper covers the structure and properties 


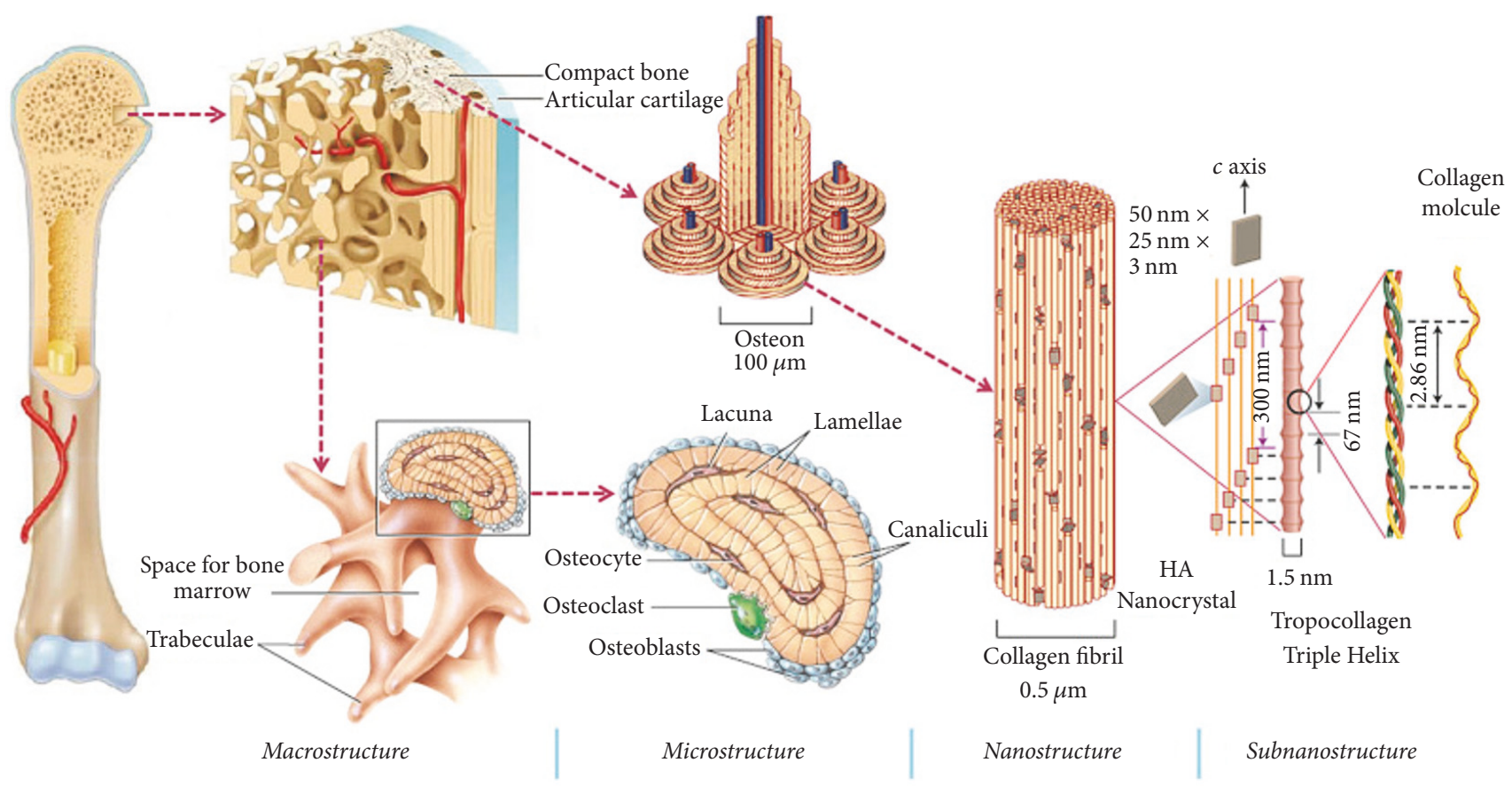

FIgURE 2: Ordered arrangement of bone structure. Copyright @Elsevier, reproduced with permission from Elsevier [43].

of natural bone, the research trends of the available biomaterials, the surface modification of biomedical implants, the implant surface coating techniques, and the potentials of EDM tool in surface treatment of biomedical implants. The mechanism of material migration and deposition during AM-EDM process was also elaborated. The advancement of EDM process from material removal to deposition process is largely contributed by the dielectric additives. However, the authors of this paper classified the dielectric fluids additives into three main classes: solid, liquid, and gasses. The role of these additive types on the surface quality of the biomedical implant was outlined. The last section of this paper stated some of the current challenges and future research directions.

\section{Natural Bones: Structure and Properties}

The larger portion of the human body is occupied by water (about 60-90 wt\%). Thus, oxygen, carbon, nitrogen, and hydrogen contain about $96 \%$ of the body weight, while the bone and teeth, which mainly contain $\mathrm{Ca}, \mathrm{Mg}$, and $\mathrm{P}$ together with electrolytes $(\mathrm{Na}, \mathrm{K}$, and $\mathrm{Cl}$ ) in blood, occupy the remaining 4\% [42]. The structure of the bone consists of organic (mainly collagen) and inorganic components (mainly CaP-based compound such as HA) as depicted in Figure 2. Collagen and HA function like a steel rod and cement in building reinforced with cement concrete, thus providing the shape, strength, toughness, and flexibility to the body [43]. Cortical bone, which bears the major weight of the body, is considered the highest load-bearing tissue in the lower limb [44]. Despite the high strength, light weight, and extreme toughness of the cortical bone, it has the highest fracture risk
[45]. In most cases, aging, accident, or diseases are the main causes of the bone failure. Although there are several attempts to study the mechanical behaviors as well as the macro-, micro-, and nanobone structures [44-46], reports revealed that the rate of bone fracture is rising every year. Thus, there is still need for thorough investigation on the biomaterials, implants design, and manufacturing.

\section{Biomaterials and Implants}

The major differences between biomaterials and other materials are their capability to associate with the human tissues without eliciting any damage or harm to the body. Biomaterials refer to materials (synthetic or natural) which are used in the form of implant/medical device to replace or repair a damaged/diseased tissue. Based on material properties, material scientists classify biomaterials into three main classes: first are the metals and alloys (Ti and $\mathrm{Ti}$ alloys, Cobalt-based alloys, stainless steel, magnesium alloys, and amorphous alloys) which are mainly based on metallic bonding. The second class are ceramics and carbon (Aluminum oxide $\left(\mathrm{Al}_{2} \mathrm{O}_{3}\right), \mathrm{HA}$, and tricalcium phosphate (TCP), carbon (C), and $\mathrm{C}-\mathrm{Si}$ ) which is built upon ionic bonding, while the last class are composite which include both the ceramics and polymers (polymethylmethacrylate (PMMA), polytetrafluoroethylene (PTFE), polysulfone (PSF), and polyethylene (PE)) [47, 48]. Medical implants may be permanent or temporary. Permanent implants, such as hip and stent, are usually implanted in a human body to serve for over one year. On the other hand, temporary implants like bone screws, plates, and suture threads are mostly made of biodegradable polymers. For long-term application, such as fracture 
TABLE 1: Routinely used metallic biomaterials and their primary applications [23, 41, 42].

\begin{tabular}{ll}
\hline Routinely used biomaterials & Applications \\
\hline Stainless steel & $\begin{array}{l}\text { Orthopedic: for total hip replacement and production of temporary devices such as plates, screws, pins, } \\
\text { and nails }\end{array}$ \\
\hline Co-based & $\begin{array}{l}\text { Orthopedic: for total joint replacement } \\
\text { Dentistry castings }\end{array}$ \\
\hline \multirow{2}{*}{ Ti-based } & Orthopedic: for stem and cup total hip replacement, production of permanent devices such as nails and \\
& face makers \\
& Dentistry: dental screws (permanent implant)
\end{tabular}

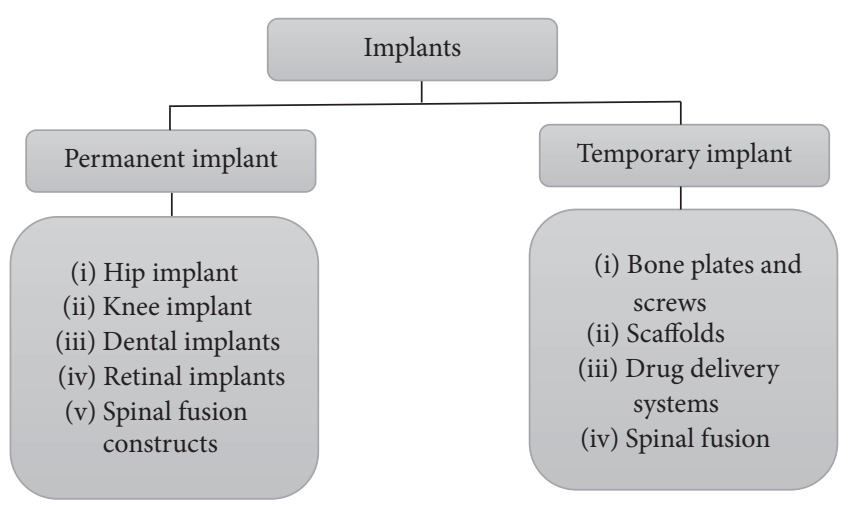

FIGURE 3: Classification of biomedical implants.

fixation or bone replacement, metallic implants are mostly employed. Figure 3 shows the classification of biomedical implants.

The application of metallic biomaterials in orthopedic can be traced back to 1895 when Lane developed the metallic plate for bone fracture fixation [21]. In recent years, the increase in population, aging, accident, and diseases has resulted in a rapid rise in bone fracture, especially knee and hip [49]. Figures 4 and 5 depict different types of total knee and hip replacement. Those with the age of 65 years and above are more prone to bone failure. The reported rate of knee replacement for ages 45-64 in United States rose from 13.1 to $27.3 / 10,000$ population in 2000 and 2006, respectively. However, for those aged 65 and above, the rate increased from 60.1 in 2000 to $88.0 / 10,000$ population in 2006 [50]. Figure 6 depicts the rate of knee replacements in the United States for hospital inpatients aged 45 and above years (2000-2006).

Based on the clinical requirements, metallic biomaterials are generally classified into three distinct generations, namely, first generation, for example, Co alloys, second generation, for example, Ti alloys, and third generation, for example, Mg alloys. The first generation aimed at developing metallic implant with high strength and nontoxic (bioinert) to the surrounding tissues. Second generation metallic biomaterials were developed to provide tight bonding between tissues and the implanted bone, thereby bridging the loosening effect of the first generations. However, it was revealed that the first and second generation biomaterials do not last long after implantation. Thus, to avoid the risk of revision surgery, third generations were developed which are mainly biodegradable [42]. A good metallic implant is expected to have the following characteristics:

(i) An outstanding biocompatibility

(ii) Good corrosion and wear resistance

(iii) Bone-matched and well-suited mechanical properties

(iv) A reasonable porosity of $20-50 \%$

(v) Good bioactivity for sufficient osteointegration [42, $51,52]$

Although new biomaterials are continuously evolving, to date, there is no developed metal or alloy that is completely bioinert or possesses all the required characteristics. Thus, there is still need to synthesize or modify the surface of new biomaterials [53]. However, among various developed biomaterials, Ti alloys are considered the most suited and possess superior characteristics compared to stainless steel and Co$\mathrm{Cr}$ alloys [23]. Currently, metallic biomaterials belonging to either stainless steel, Co-based alloys, or Ti-based alloys were the only materials routinely used for orthopedic and dental applications as summarized in Table 1. Thus, implants belonging to these three classes of biomaterials are already approved by the United State Food and Drugs Administration (FDA) [23].

On the other hand, new generations of metallic biomaterials are currently emerging by altering the alloying composition, the microstructure, and the processing technology of the previous biomaterials. For instance, Ni in stainless steel was replaced with other nontoxic elements to produce Ni-free systems such as FeCrN, FeCrMoN, and FeCrMnMo. The wear resistance of Co-Cr alloy was improved by alloying it with $\mathrm{Zr}$ and $\mathrm{N}$ and by increasing the carbon content. The high elastic modulus in Ti-alloy was greatly reduced to produce $\alpha$-Ti alloys with the lowest modulus of elasticity $[54,55]$. However, porosity was intentionally introduced to some metallic biomaterials which significantly reduced the elastic modulus of the alloys [51]. In addition, novel systems of biomaterials called BMGs were recently introduced in biomedical field [28]. Nowadays, several authors are working on BMGs potentialities especially for industrial and biomedical use [56]. Table 2 compares the characteristics of stainless steel, Co-based alloys, Ti-based alloys, and BMGs in biomedical application. The mechanical properties of these alloys are compared to that of cortical bone in Figure 7. 
TABLE 2: Characteristics of nonbiodegradable metallic biomaterials (grades ranged from 5, excellent score, to 1 , poor score) [22, 23, 28, 57].

\begin{tabular}{|c|c|c|c|c|}
\hline Characteristics & Stainless steel & Co-based alloys & Ti-based alloys & BMGs \\
\hline \multicolumn{5}{|l|}{ Machinability } \\
\hline Conventional & 5 & 1 & 1 & 2 \\
\hline Advanced & 5 & 3 & 3 & 4 \\
\hline Corrosion resistance & 2 & 3 & 4 & 5 \\
\hline Wear resistance & 2 & 2 & 1 & 5 \\
\hline Biocompatibility & 1 & 2 & 3 & 2 \\
\hline Bioactivity & 1 & 1 & 1 & 1 \\
\hline
\end{tabular}

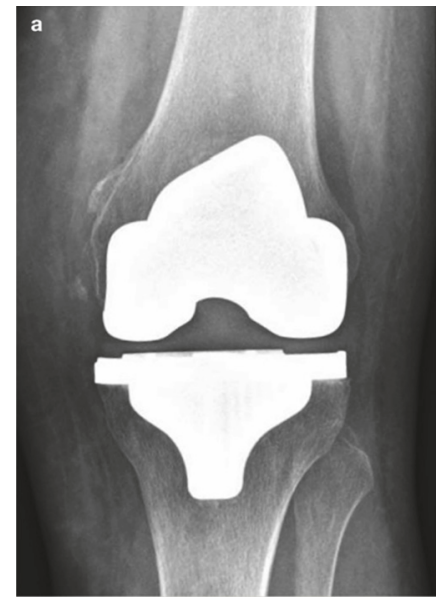

(a)

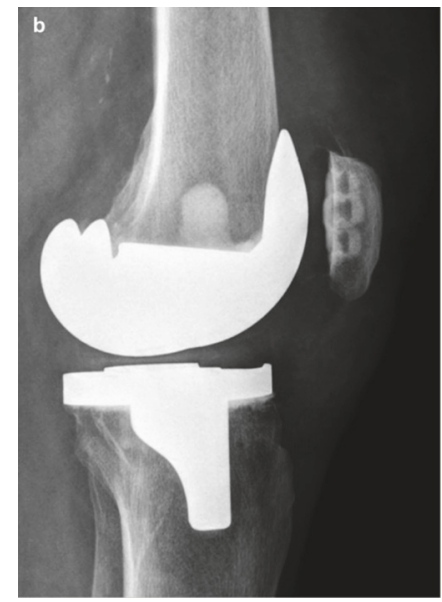

(b)

FIGURE 4: Anteroposterior (a) and lateral (b) radiographs demonstrating a total knee replacement [49].

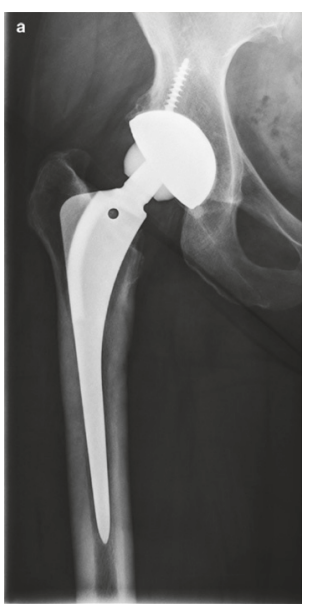

(a)

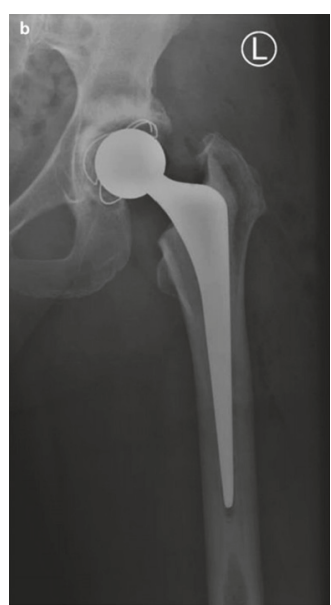

(b)

FIGURE 5: (a) Uncemented total hip replacement (THR) with a ceramic on ceramic bearing. (b) Cemented THR using the Exeter system with a metal on plastic bearing [49].

3.1. Implant Failure. Even though most of the synthesized implants are much stronger than the human bone, a high number of femoral and dental implants were reported being failed at an early stage of implantation. However, the most successful orthopedic implants last for about 15 years, which is comparatively shorter than the lifespan of human (even the elderly person with a life expectancy of 17.9 years) [42]. Thus, the patient mostly undergoes a revision surgery, which is not normally recommended. The possible causes of this implant premature failure are due to several reasons such as incompatible mechanical properties of the implant or fixation device, the development of undesired osteointegration between living bone and the synthetic surface, and poor implant surface finishing as well as poor corrosion and wear resistance. To solve this problem, several researchers attempt to modify the implant surface through various methods. 


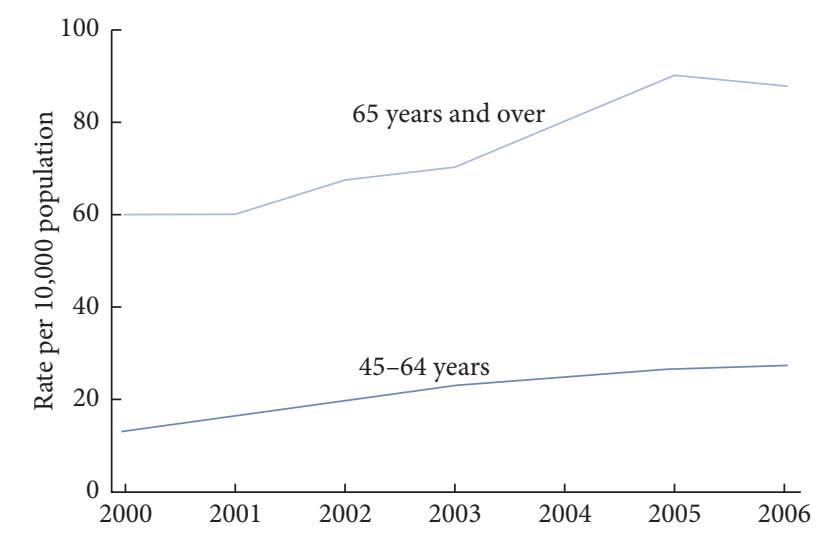

FIGURE 6: Rate of knee replacements in United States for hospital inpatients aged 45 and above years (2000-2006) [50]. Note: rates for 2000-2006 were calculated using US Census Bureau 2000-based postcensal population estimates. Source: CDC/NCHS, National Hospital Discharge Survey.

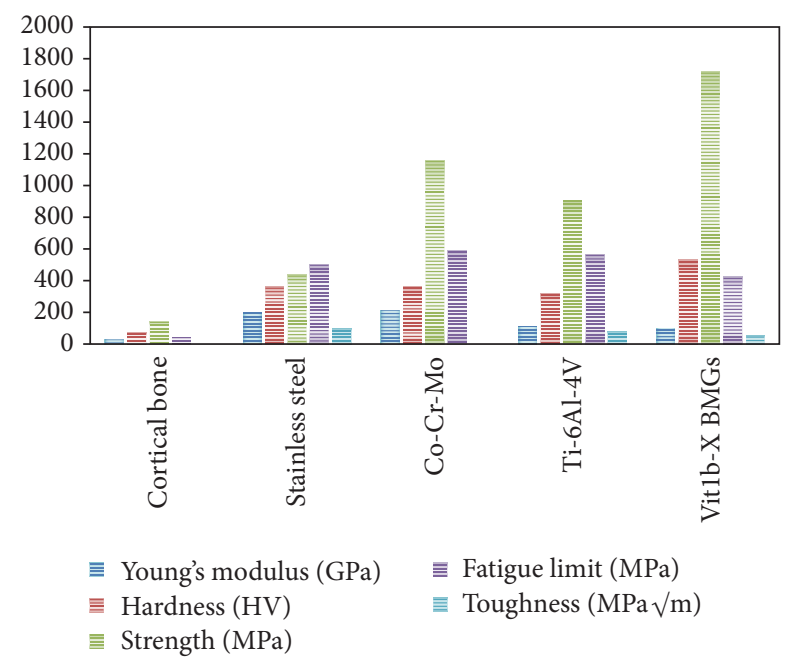

FIGURE 7: Comparison of mechanical properties of the cortical bone and the most commonly used metallic biomaterials [30, 58, 59].

Table 3 critically analyzes some reports on failed orthopedic (femoral) and dental implants. Figures 8 and 9 show the failed femoral plate and dental (inner screw) implants, respectively.

3.2. Surface Treatment of Metallic Implant. Despite various attempts to select a material with alloying elements that suit the essential elemental constituents in the human body, there are still some problems of cell adhesion and tissue inflammation which normally developed in the bone-implant interface. This is because the surface of a biomedical implant is always exposed to the dynamic bioenvironment. However, so many reactions take place between the implant surface and the surrounding tissues due to mismatch of the implant surface topography, surface contamination, and chemical and mechanical properties with the host tissues [93]. Although most of the developed implant surface coating techniques are still in the experimental stage, surgeons, bioengineers, and material scientists believed that surface treatment (modification) remained the key solution to these issues [41, 94]. The surface modification may be morphological (roughness, porosity, texture, and topography) or chemical as elaborated in Figure 10. Morphological surface treatment is considered as the most crucial in the field of biomedical. Through surface modification, the wear and corrosion rate of the implant can be greatly improved. However, modified implant can interact and nicely adhere to the surrounding tissues with appreciable biocompatibility and osteointegration [42].

3.2.1. Deposition of HA/CaP-Based Compounds. Calcium phosphate constitutes the major structure of the bone and teeth. Since 1920s, there are several attempts to repair fractured/diseased hard tissues using CaP-based compounds. However, 40 years ago, first CaP-based compound was commercially launched and applied clinically [95]. Since then, the surface treatment of orthopedic and dental implants mainly focused on inorganic HA and/or CaP compounds. Depending on the preparation method, CaP-based implant coating was revealed to improve the mechanical characteristics, biocompatibility, and osteointegration of the implanted bone/tooth $[73,85,96]$ Table 4 displays the requirement of HA coatings. Although several methods of depositing HA and $\mathrm{CaP}$ have been reported $[68,74,80,83]$, new techniques of preparing and applying a coating on the implant surface are contentiously evolving. These processes are mainly classified into physical and chemical deposition methods. Physical deposition techniques include the following: thermal spray techniques (atmospheric plasma spray (APS), suspension plasma spray, vacuum plasma spray, etc.), pulse laser deposition (PLD) (matrix assisted and ion beam assisted), and sputtering process (radio frequency and direct frequency), while chemical deposition techniques covered sol-gel, dip coating, hot (isostatic) pressing, microarc oxidation (MAO) (anodic spark oxidation and plasma electrolytic oxidation), electrostatic spray deposition (ESD), and electrophoretic coating $[69,77,84,97]$. The downside of physical methods is their inability to deposit organic compound on the substrate. On the other hand, chemical deposition methods which developed recently are gaining more attention. They serve as hybrid methods for applying both organic (natural bone components) and inorganic compounds on the implant surface [98]. Selection of proper coating method determines the long-term performance and stability of the implanted tissue/bone. Plasma spray which involves spraying of molten (extremely heated) $\mathrm{CaP} / \mathrm{HA}$ on the substrate is the most commonly used and commercially available technique. Besides the high deposition rates of this method, issues like the need for very high temperature $\left(>10,000^{\circ} \mathrm{C}\right)$ and formation of the amorphous coating limit its application $[70,75]$. The benefits and drawbacks of different $\mathrm{CaP} / \mathrm{HA}$ coating methods are summarized in Table 5.

\section{Overview of Electrical Discharge Machining}

The concept of electrical discharge machining (EDM) can be traced back to 1751 when Benjamin Priestly observed a 
TABLE 3: Critical review on some premutually failed orthopedic and dental implants.

\begin{tabular}{|c|c|c|c|}
\hline Author, year & Material (implant type) & Expected causes/effect of implant failure & $\begin{array}{l}\text { Implant duration } \\
\text { (months) }\end{array}$ \\
\hline Stronach et al. [60], 2016 & $\begin{array}{l}\text { No evidence of material } \\
\text { (Hip stem) }\end{array}$ & $\begin{array}{l}\text { (i) Fretting corrosion } \\
\text { (ii) Crevice corrosion } \\
\text { (iii) Fatigue failure } \\
\end{array}$ & 72 \\
\hline $\begin{array}{l}\text { Guerra-Fuentes et al. [61], } \\
2015\end{array}$ & $\begin{array}{l}\text { 316L stainless steel } \\
\text { (Femoral bone) }\end{array}$ & $\begin{array}{l}\text { (i) Bone callus formation } \\
\text { (ii) Fretting wear of fixation screws } \\
\text { (iii) Fatigue failure } \\
\text { (iv) Plate implant fractured }\end{array}$ & 4 \\
\hline $\begin{array}{l}\text { Hernandez-Rodriguez et al. } \\
{[62], 2015}\end{array}$ & Ti-6Al-4V (dental) & $\begin{array}{l}\text { (i) Bone resorption } \\
\text { (ii) Rough surface finish in the screw } \\
\text { (iii) Crack and fractured }\end{array}$ & 6 \\
\hline Gervais et al. [63], 2016 & $\begin{array}{l}\text { 316L stainless steel } \\
\text { (femoral bone) }\end{array}$ & $\begin{array}{l}\text { (i) High-fatigue cycles }\left(10^{6} \text { cycles) }\right. \\
\text { (ii) Unexpected fall of the patient }\end{array}$ & $<24$ \\
\hline Kanchanomai et al. [64], 2008 & $\begin{array}{c}\text { No evidence of material } \\
\text { (femoral bone) }\end{array}$ & $\begin{array}{l}\text { (i) Fatigue crack in the compression hole } \\
\text { (ii) Fatigue crack in the locking hole }\end{array}$ & 0.27 \\
\hline Amel-Farzad et al. [65], 2007 & $\begin{array}{l}\text { Stainless steel (femoral } \\
\text { bone) }\end{array}$ & $\begin{array}{l}\text { (i) Corrosion fatigue } \\
\text { (ii) Crevice corrosion pitting } \\
\text { (iii) Nonstandard material (Supplied in the alloy) }\end{array}$ & 24 \\
\hline Marcomini et al. [66], 2014 & Stainless steel (femoral) & $\begin{array}{l}\text { (i) Poor material quality } \\
\text { (ii) High phosphorous content (nonstandard) } \\
\text { (iii) Segregation at grain boundaries } \\
\text { (iv) Crack propagation (cyclic loading) } \\
\text { (v) Loss of ductility due to cold work }\end{array}$ & $\begin{array}{l}\text { 1st failed at } 4 \\
\text { sent back to the } \\
\text { manufacturer, and } 2 \mathrm{nd} \\
\text { failed at } 6\end{array}$ \\
\hline
\end{tabular}

TABLE 4: FDA HA coating requirement [67].

\begin{tabular}{lcccccc}
\hline Crystallinity & Phase purity & CaP ratio & Density & Heavy metals & Tensile strength & Shear strength \\
\hline Min. 62\% & Min. 95\% & $1.67-1.76$ & $2.98 \mathrm{~g} / \mathrm{cm}^{3}$ & $<50 \mathrm{ppm}$ & $>50.8 \mathrm{MPa}$ & $>22$ \\
\hline
\end{tabular}

TABLE 5: Benefits and limitations of CaP-based coating methods.

\begin{tabular}{lcll}
\hline Coating methods & Thickness & Benefits & Drawbacks \\
\hline Sol-gel & $<1 \mu \mathrm{m}$ & $\begin{array}{l}\text { Coat complex shapes, low cost (thin), low } \\
\text { processing temperature, high purity }\end{array}$ & $\begin{array}{l}\text { Controlled atmosphere required, costly } \\
\text { raw materials }\end{array} \quad$ [34, 68, 69] \\
\hline Sputter processes & $0.5-3 \mu \mathrm{m}$ & $\begin{array}{l}\text { Thickness uniformity on Coat flat } \\
\text { substrate, good adhesion, dense coating }\end{array}$ & $\begin{array}{l}\text { High cost, time consuming, produces } \\
\text { amorphous coatings }\end{array}$ \\
\hline Plasma spray & $<20 \mu \mathrm{m}$ & $\begin{array}{l}\text { High deposition efficiency, low cost, } \\
\text { reduced risk of coat degradation }\end{array}$ & $\begin{array}{l}\text { High temperature led to grain growth, } \\
\text { Amorphous coatings, poor adhesion }\end{array}$ \\
\hline PLD & $0.05-5 \mu \mathrm{m}$ & $\begin{array}{l}\text { Crystalline and amorphous coating, } \\
\text { dense and porous coating }\end{array}$ & $\begin{array}{l}\text { High cost, time, no uniformity in } \\
\text { thickness consuming, surface need to be } \\
\text { pretreated }\end{array}$ \\
\hline ESD & $1-10 \mu \mathrm{m}$ & $\begin{array}{l}\text { Low cost, uniformity in coating flat } \\
\text { substrate }\end{array}$ & $\begin{array}{l}\text { Coats only visible area, it is fragile } \\
\text { Electrophoretic coating }\end{array}$ \\
\hline $0.1-2.0 \mathrm{~mm}$ & $\begin{array}{l}\text { Uniformity in coating thickness, coat } \\
\text { complex substrate, rapid deposition rate }\end{array}$ & $\begin{array}{l}\text { Produces cracks coated surface, high } \\
\text { sintering temperature required }\end{array}$ \\
\hline Hot (isostatic) pressing & $0.2-2.0 \mathrm{~mm}$ & $\begin{array}{l}\text { Dense coating is achieved, coat any } \\
\text { dimension }\end{array}$ & $\begin{array}{l}\text { Requires high temperature, complex } \\
\text { shapes cannot be coat, high cost, } \\
\text { mismatch thermal expansion, differences } \\
\text { in elastic property }\end{array}$ \\
\hline [83, 84]
\end{tabular}



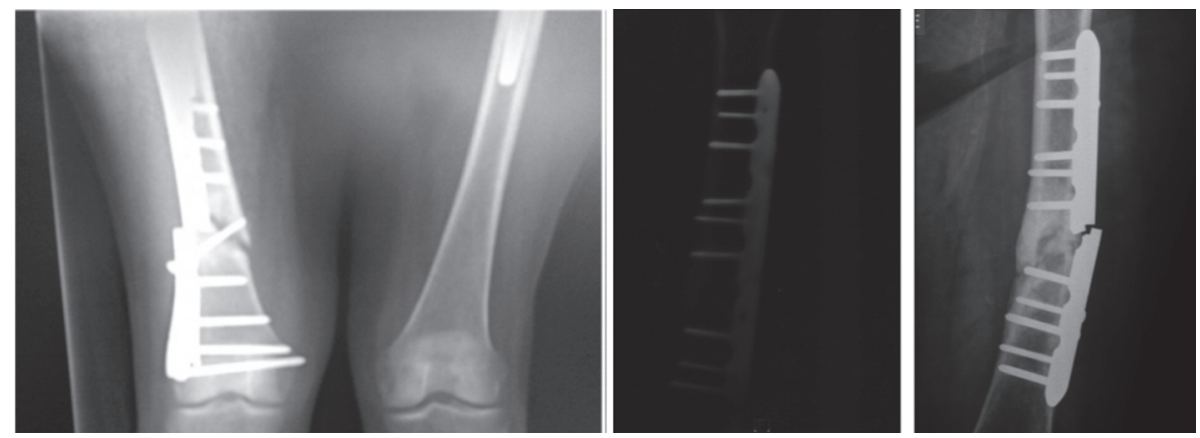

FIGURE 8: Bone and the failed supracondylar plates before and after being fractured. Copyright @Elsevier, reproduced with permission from Elsevier $[61,66]$.
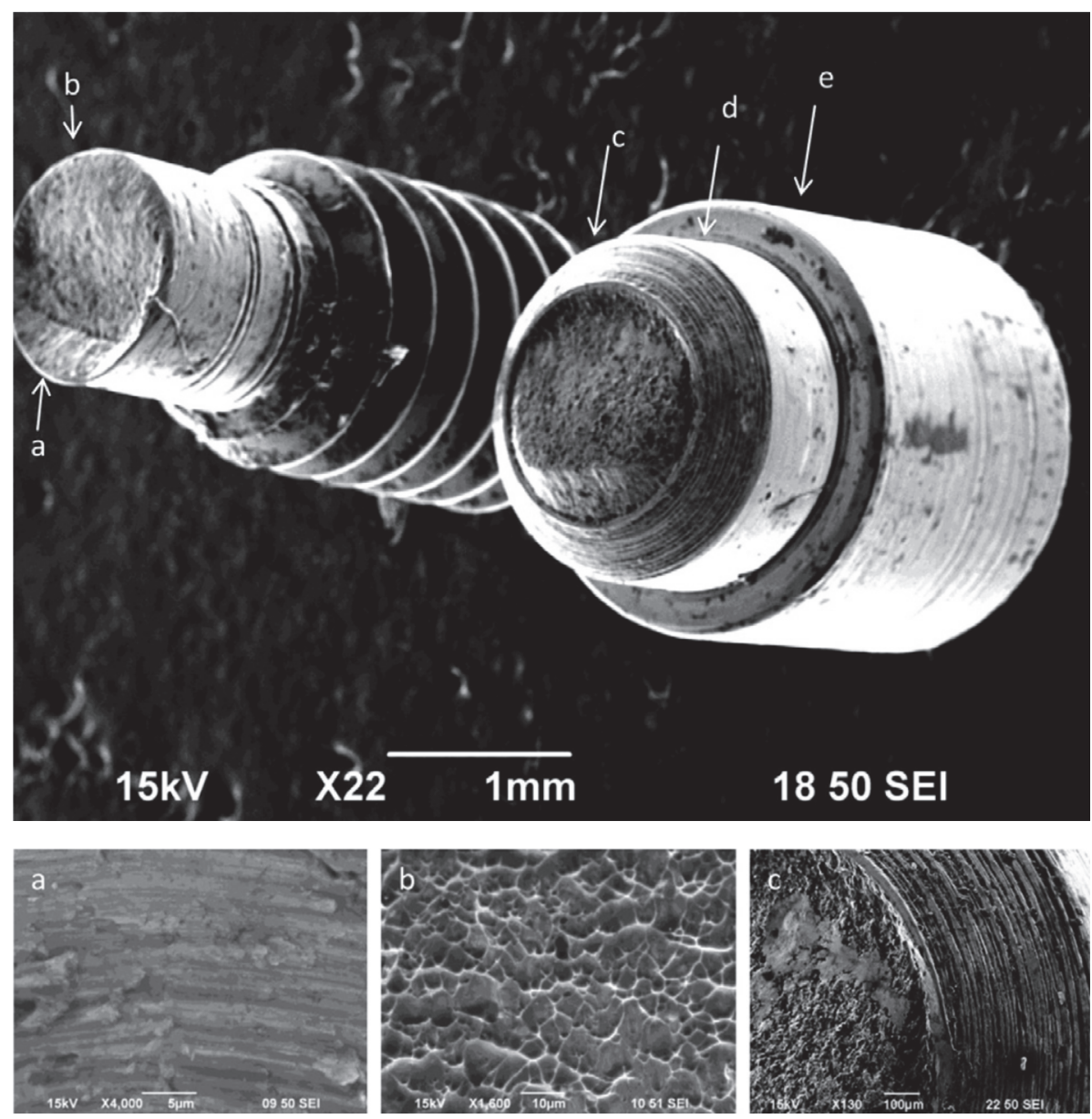

FIGURE 9: SEM images depicting different regions of the fractured dental implant surface. Copyright @Elsevier, reproduced with permission from Elsevier [62].

material removal between two electrodes through electrical discharging. However, material removal through EDM process was developed during the era of World War II. Since then, there has been an upsurge in developing the EDM process, including the machining parameters' setting and the performance measures. One of the novelties of the EDM process over traditional machining techniques is its ability to shape any electrically conductive material. In addition, certain amount of material can also be deposited on the machined surface, thereby enhancing its surface characteristics. EDM is demonstrated to be a hitch-free method that can automatically be used to produce a threedimensional deep and complex cavity $[99,100]$. The working principle of EDM is a thermoelectrical phenomenon which uses electricity and thermal energy to generate sparks and erodes both the electrodes' surfaces. A series of repetitive sparks are produced through a high supply voltage at a narrow gap between the electrodes. Thus, at each spark, a minute 


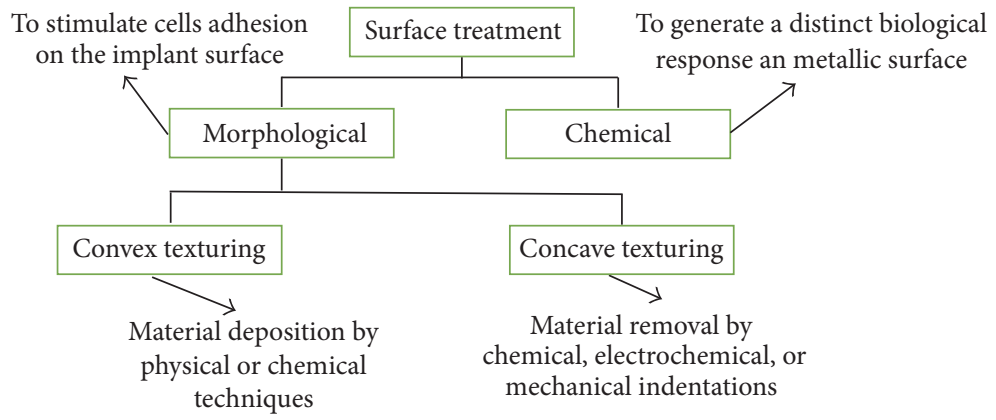

FIgURE 10: Classification of surface modification [21, 52].

particle of material is removed from the electrodes' material in the form of debris [101]. In most cases, the electrodes are immersed completely in the dielectric fluid, which is normally in the form of mineral oil or deionized water $[102,103]$. The EDM performance depends strongly on the proper setting of both electrical (discharge current, discharge time, OFF-time, supply voltage, and tool-electrode polarity) and nonelectrical (flushing type, machining time, machining depth, dielectric medium, and electrode speed) machining parameters. Several authors have attempted to outline the EDM parameters and their influence on the machining performance. Pulse-on time, supply current, gap voltage, and powder concentration have been identified to have a major influence on the machining characteristics like material removal rate (MRR), tool electrode wear rate (TWR), and surface roughness (SR). However, a lot of studies have been made to optimize the performance of these parameters on different materials [104-111].

4.1. EDM Dielectric Fluids. The dielectric fluid plays a significant role in insulating the electrodes, clearing the debris from the machining gap, and cooling a very high temperature $\left(800-1200^{\circ} \mathrm{C}\right)$ generated in the surface. Some EDM machines are customized with certain types of working fluids. However, in several situations, there is a need to select proper dielectric fluid. Generally, sinking EDM uses mineral oils while microand wire-cut EDM deal with deionized water [112]. These fluids have some benefits as well as limitations in different applications. For instance, in biomedical applications, deionized water stimulates the corrosion rate of EDMed implant surface, while oils based dielectric fluids burn and release carbons, which react to the alloying elements and form a very hard carbide surface. Leão and Pashby [113] reported the current trends on the use of environmentally friendly dielectric fluids and confirmed that water-based dielectric fluids will overrule the use of oil-based fluids. On the other hand, to mitigate the effect of dielectric fluid on health and environment, dry or semidry EDM was employed, whereby gasses such as oxygen and nitrogen are used as EDM working fluid [114-120].

4.2. Evolution of EDM Applications. In the past decades, EDM process is commonly used in the manufacturing of cutting tools, molds, and dies $[110,121,122]$. To reduce the cost of oil dielectric fluid and the environmental pollution, dry (air) EDM was introduced. Kunieda et al. [123] established that EDM can be achieved in gas especially in machining 3D shape. Through dry EDM, small or zero tool-electrode wear with improved surface quality can be achieved [114]. Aside from material removal capability, EDM process is also considered as surface modification/alloying technique, due to the evidence of material transfer which occurs between the electrodes and the suspended dielectric fluid additives during the process [124-126]. The development of smaller (microsize) products widens the applications of EDM to produce microcavities with high-aspect ratio [127], micro molds and dies [128], and micro rotational components [129]. The EDM productivity and the surface quality of the machined surface were greatly enhanced when dry EDM was augmented with the magnetic field $[130,131]$. Thus, a wide application of EDM in the manufacturing of automobiles, aerospace, and nuclear components with a polished surface finishing which requires no secondary process has been recorded [9, 132-135]. Recently, EDM process evolved in the biomedical field owing to its ability to generate a mirror-like, extremely hard, and a biocompatible nanoporous surface through the phenomenon of material migration. A work presented by Peng et al. [19] shows a generation of nanoporous biocompatible layer on the EDMed Ti surface. Sales et al. [136] and Shabgard and Khosrozadeh [137] modify the surface of Ti-6Al-4V by adding calcium and carbon nanotubes in the dielectric fluids, respectively. The surface of the biodegradable magnesium alloy was improved when PM-EDM uses zinc powder [17]. The advancement of EDM process based on applications is summarized in Figure 11.

4.3. Additive Mixed-Electrical Discharge Machining. Using oil-based or deionized water as the EDM dielectric fluid is not enough to provide the satisfactory surface quality, especially in automobiles, aeronautics, and medical field, where a special surface tolerance is required. The substance added during AM-EDM may be grouped into three main classes. These are solid additives such as metallic powders, liquid additives like surfactant, urea solution, and calcium aqueous solution, or gaseous additives like nitrogen and oxygen gasses. The additives mixed with the dielectric fluid not only stabilize the EDM process but also improve the EDM efficiency and quality of the machined surface [138, 139]. The EDM performance, tool-electrode life, and quality of the 


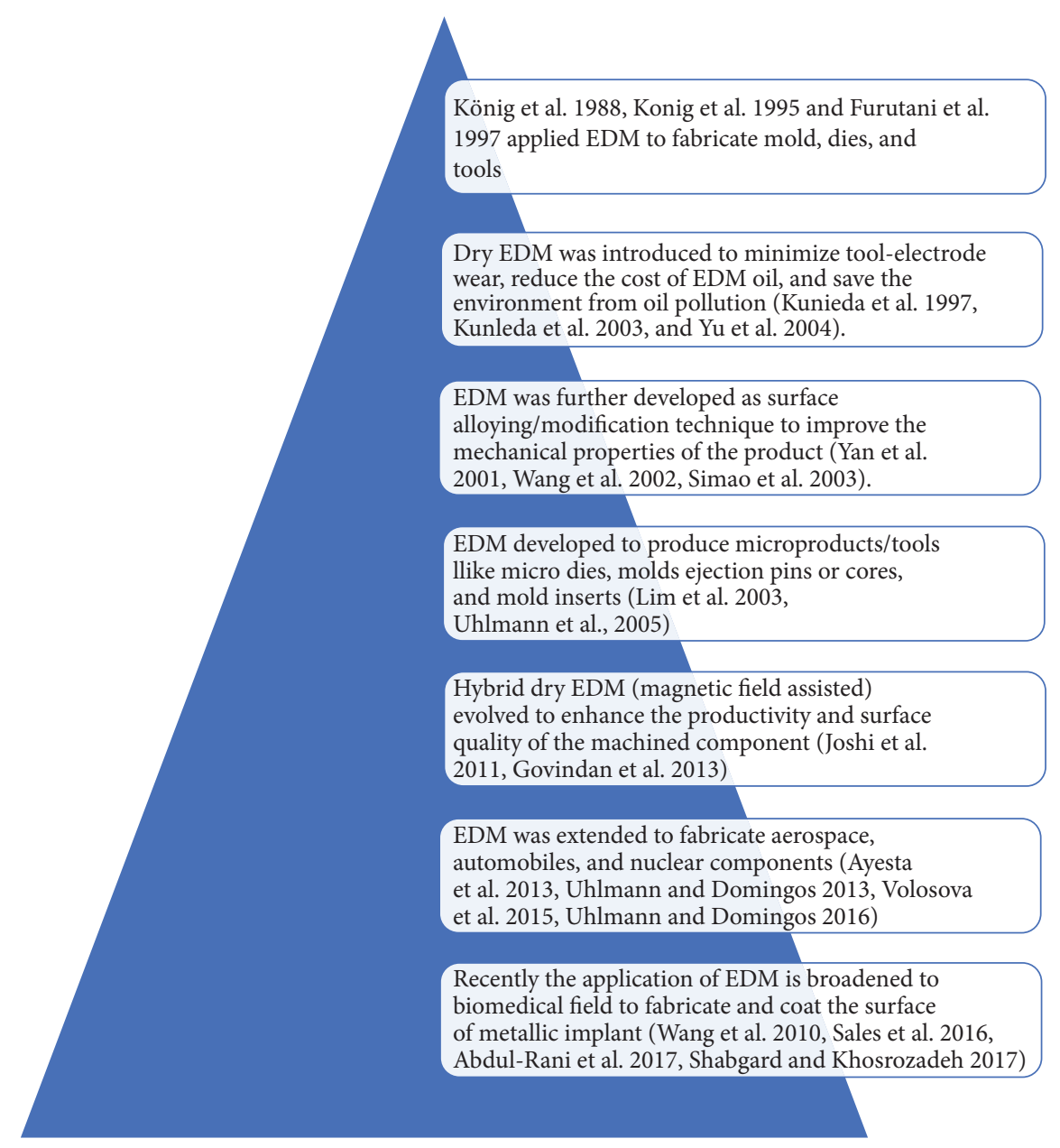

FIGURE 11: EDM process advancement based on applications.

machined component depend greatly on the additive type, size, concentration, and properties [140, 141]. Figure 12 shows a complete schematic diagram of AM-EDM.

4.3.1. Solid Additives (PM-EDM). The addition of solid substances to the dielectric fluid in the form of powder particles (PM-EDM) stabilizes the EDM process and improves its machining efficiency by decreasing the insulating strength of the suspended dielectric fluid and increasing the discharge gap. Several reports on adding different kinds of metallic powder have been documented. Al-Khazraji et al. [104] reported an improvement in the fatigue life and the recast layer thickness by adding $\mathrm{SiC}$ microsize powder to the dielectric fluid. The surface morphology and surface roughness of PM-EDMed AISI D2 steel were greatly enhanced when Ti nanopowder was added to the dielectric fluids [88]. Addition of chromium powder into the dielectric fluid notably improved the surface hardness and the surface finish of the machined tool steel during PM-EDM [142]. Singh et al. [143] studied the effect of EDM machining parameters without powder and with tungsten powder mixed dielectric fluid. Reduced recast layer thickness and enhanced surface finish were achieved after the PM-EDM of SiC. Bajaj et al. [144] present a laudable review on the use of micro- and nanosize powder particles and revealed that the powder particles in nanoform are superior to microsize particles, in terms of surface quality and MRR improvement. An improved surface quality, MRR, and TWR were significantly observed when carbon nanotube was added to the dielectric fluid during the EDM of Ti-6Al-4V [137]. Figure 13 depicts SEM micrographs of surfaces machined with and without added powder. It can be observed that EDMed surface (Figure 13(a)) has thicker and irregular white layers when compared with PMEDMed surface (Figure 13(b)).

4.3.2. Liquid Additives. Liquid substances may be used purely or augment with the powder particles mixed with the dielectric fluid to enhance the efficiency of the EDM machine and improve the properties of the machined surface. Addition of surfactant to the dielectric fluid improved the overall EDM performance by increasing the conductivity of the suspended powder particles and reducing its agglomeration. This results in reduced SR and recast layer thickness of the modified titanium alloy as shown in Figure 14 [145]. Yan et al. [146] studied the influence of urea solution added to the water dielectric fluid during EDM of pure titanium. Urea mixed 


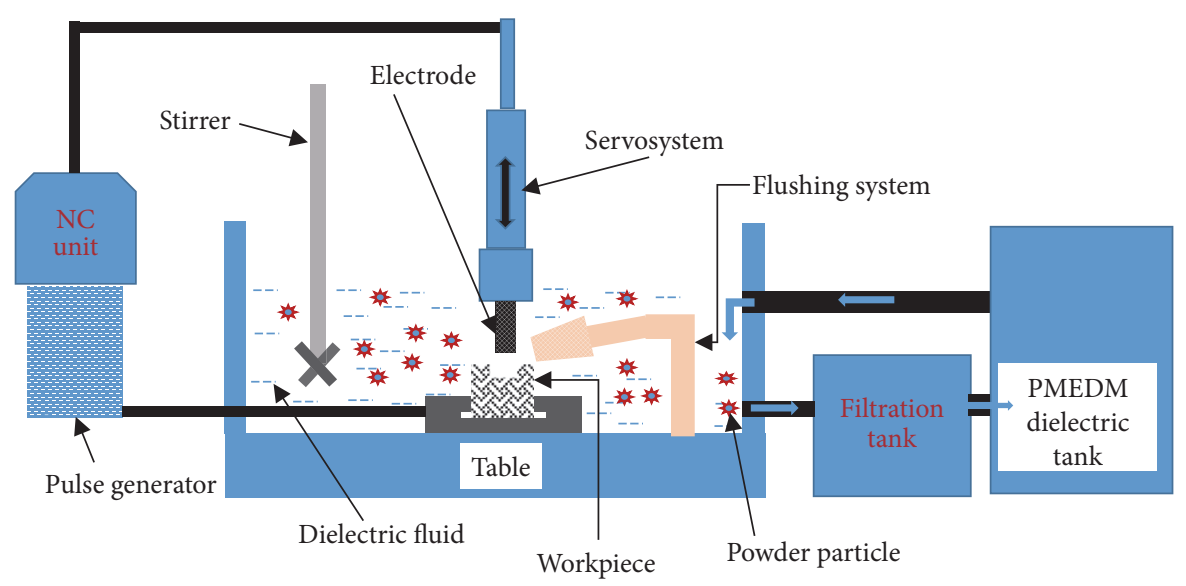

FIGURE 12: Schematic diagram of complete AM-EDM experimental setup.

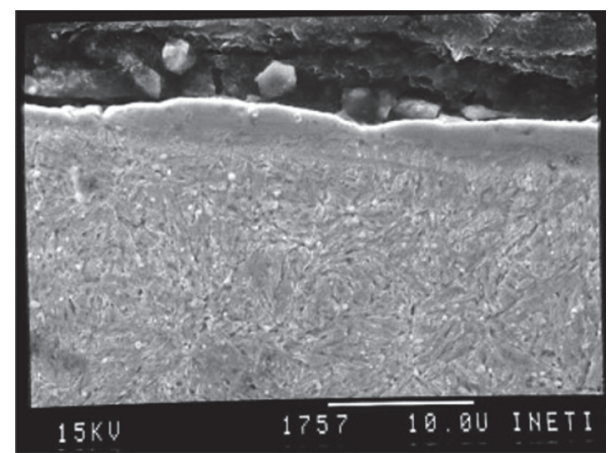

(a)

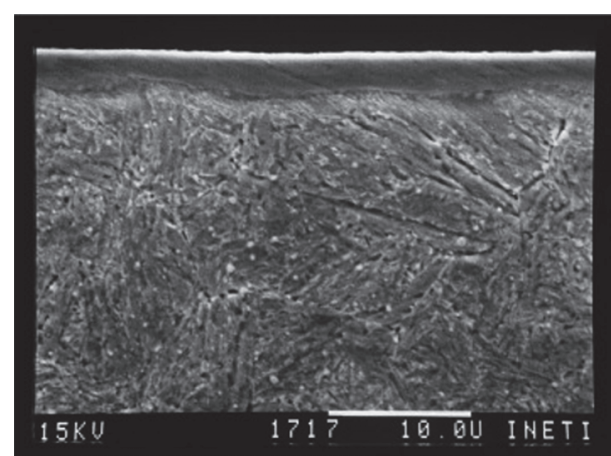

(b)

FIGURE 13: SEM micrograph of (a) EDMed (b) PMEDMed surfaces. Copyright @Elsevier, reproduced with permission from Elsevier [138].

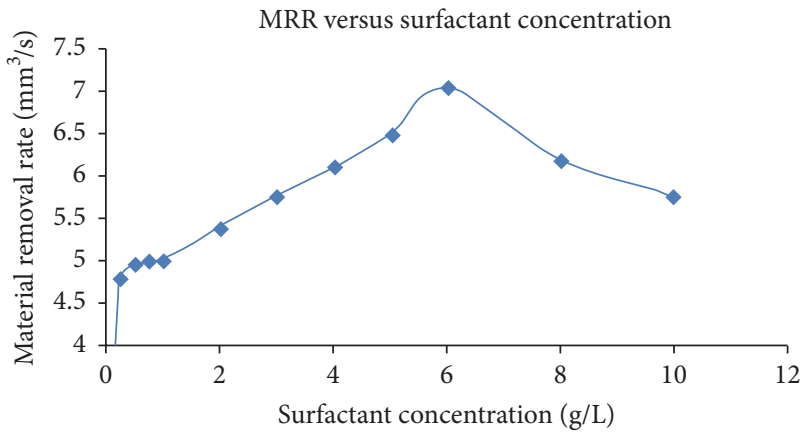

(a)

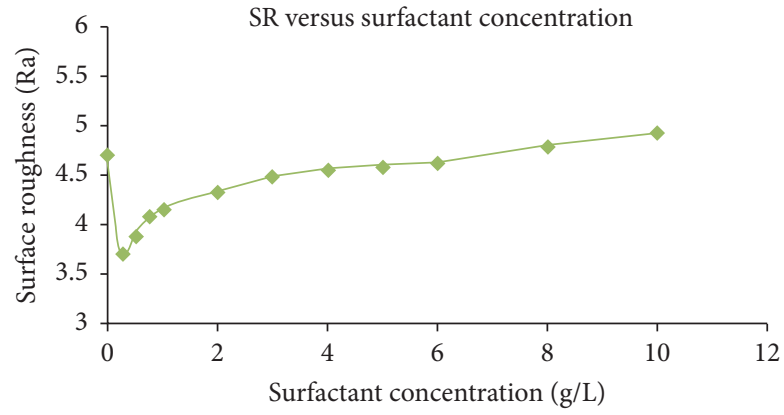

(b)

FIGURE 14: The effect of added surfactant on MRR and SR [38].

dielectric fluid decomposed and liberated nitrogen, which melted and migrated to the workpiece-electrode surface.

4.3.3. Gaseous Additives (Dry EDM). To reduce cost of liquid (oil-based) dielectric fluid and overcome its environmental pollution and health hazard effect, dry EDM was introduced by using a gaseous substance like nitrogen, argon, or oxygen gas as a working fluid. Figure 15 shows a schematic diagram of oxygen mixed-EDM. The quality of the machined surface and the rate of material removal depend on the type of the gas used [147]. For instance, machining with oxygen mixed dielectric fluids produces deeper and wider craters as depicted in Figure 16. During this process, a high-speed air is usually blown into the discharge gap which removes away the debris from the cutting zone. The greatest improvement in surface quality with discontinuous recast layer as well as a thin heat affected zone is recorded [120]. Yu et al. [114] used oxygen as dielectric fluids to assist in the machining 


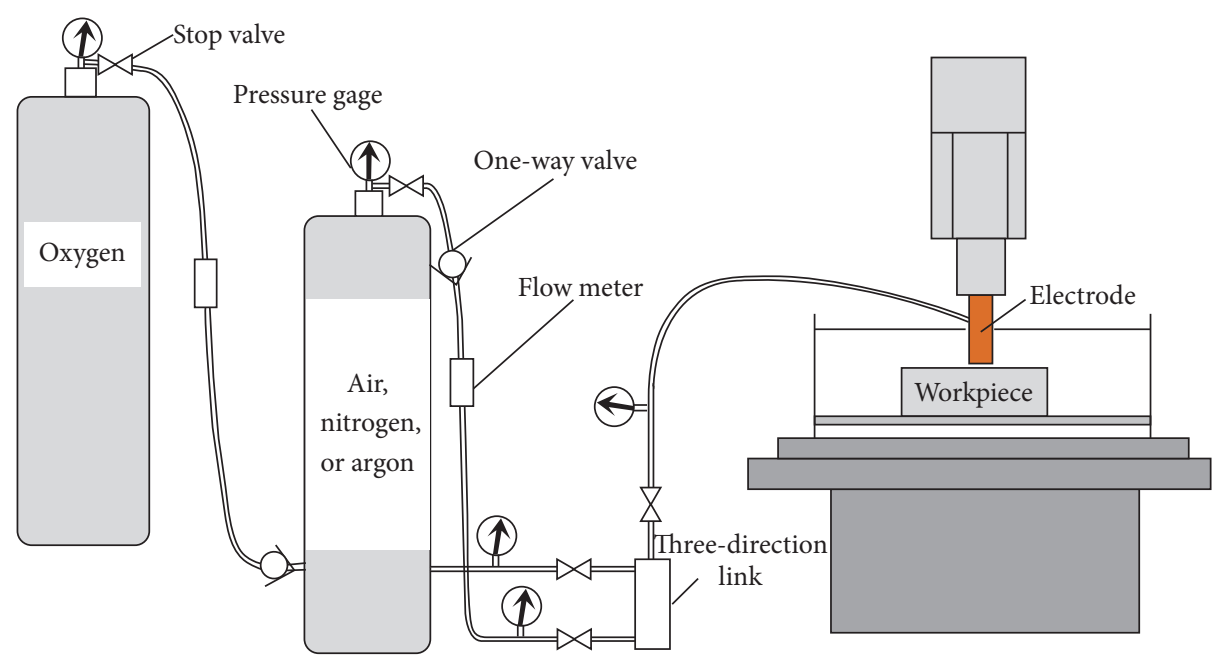

FIGURE 15: Schematic diagram of oxygen mixed-EDM. Copyright @Elsevier, reproduced with permission from Elsevier [147].

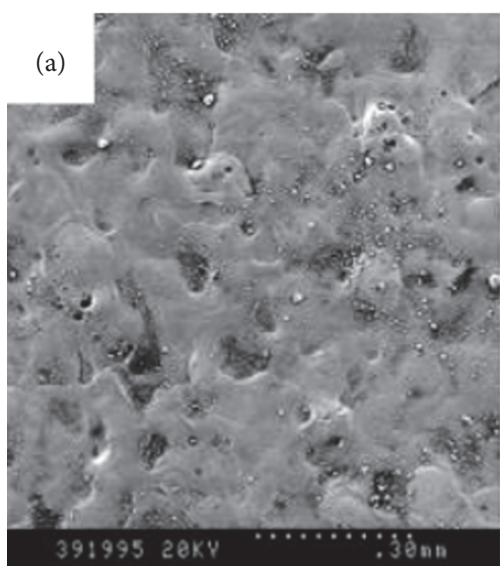

(a)

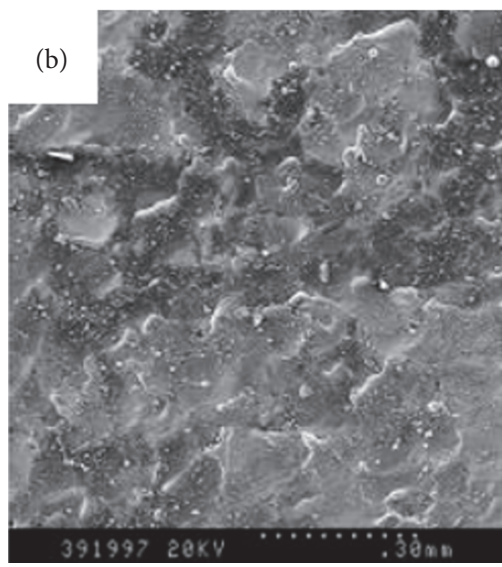

(b)

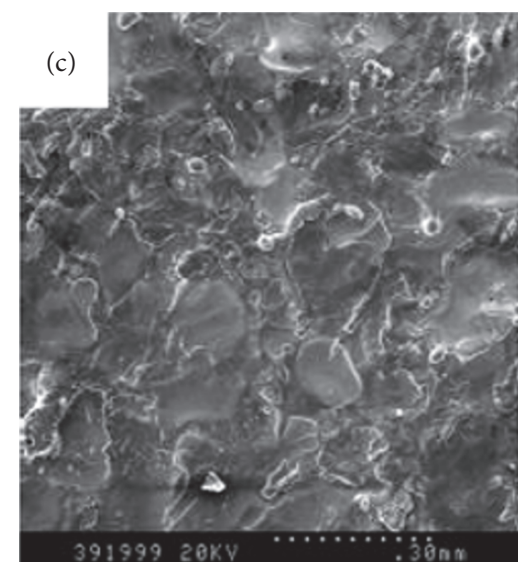

(c)

FIGURE 16: Surface topography of the machined samples in (a) argon, (b) nitrogen, and (c) oxygen. Copyright @Elsevier, reproduced with permission from Elsevier [147].

of cemented carbide. It was found that dry machining is more efficient, especially when cost and machining time are considered. In a study by Dhakar and Dvivedi [148], neardry EDM (liquid and air) of high-speed steel produces a finer surface, negligible tool-electrode wear, and thinnest recast layer when compared to conventional EDM. During dry $\mathrm{EDM}$, the debris in the machining gap can be easily removed, thereby overcoming the problem of its reattachment to the electrodes surfaces. Huang et al. [149] reported the use of nitrogen gas as the dielectric fluids. A nanostructured surface in the form of $\mathrm{TiN}$ and $\mathrm{CrN}$ with extreme hardness and excellent adhesion was found.

\section{AM-EDM as Potential Surface Treatment Technique for Biomedical Implants}

The applications of EDM are broadening from mere tools and dies, to fabrication and shaping of automobiles, aerospace, nuclear components, and, recently, to fabrication and surface treatment of biomedical implant. Despite the complexity of the EDM process, several studies have revealed the wide potentialities of this process in the biomedical field, especially with regard to the fabrication and surface modification of metallic implant. This is evident when a significant material transfer from the tool electrode and the suspended dielectric additives to the workpiece-electrode surface was observed during the EDM process. This serves as a strong route of providing a well finished and qualitative machined surface. In addition to generation of extremely hard, nanofinished, and nonporous surface, EDM produces a bioactive and a biocompatible layer on the implant surface through the concept of material migration.

5.1. Mechanism of Material Migration. During the EDM process, materials from the tool electrode and the additives in the dielectric fluids are transferred and deposited on the 


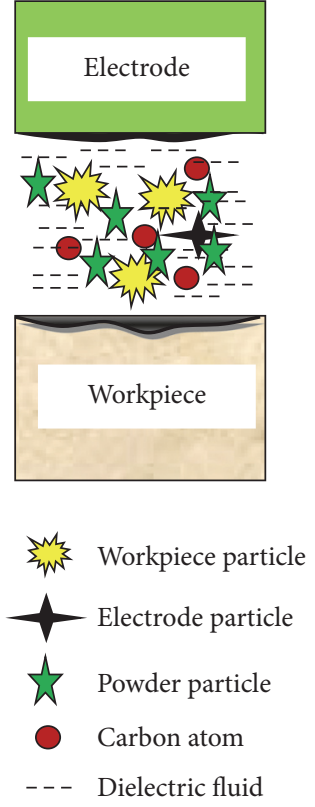

(a)

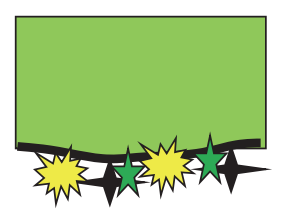

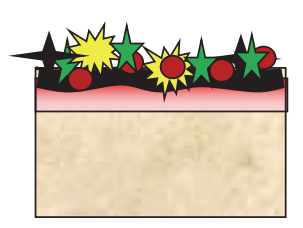

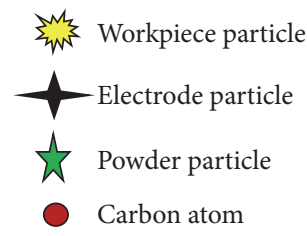

(b)
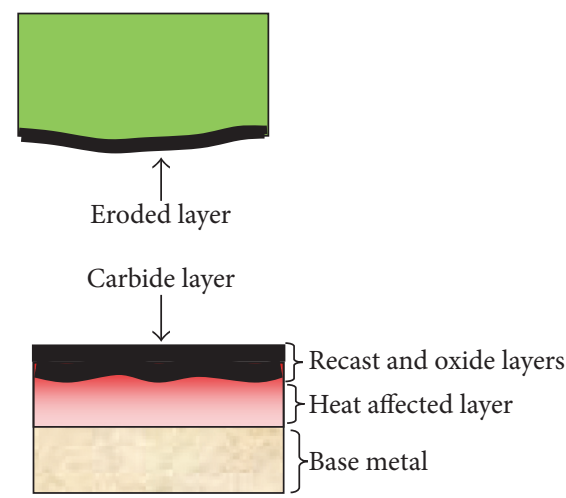

(c)

FIGURE 17: Mechanism of material migration and deposition. (a) Initiation of spark. (b) Carbon atoms, powder, and tool-electrode particles adhered on the electrodes surfaces. (c) Formation of three distinct layers.

workpiece-electrode surface. Batish et al. [39] investigated the mechanism of material transfer during EDM of three different die steel samples, thus confirming a reasonable deposition of tool-electrode material and powder particles on the EDMed surface. Gülcan et al. [150] reported a substantial deposition of tool-electrode materials on the workpieceelectrode surface after AM-EDM. Thus, a very hard surface with strong abrasion and corrosion resistance surface was achieved. It is believed that material transfer by AM-EDM altered the chemical content, mechanical properties, and the metallurgical structure of the machined surface, thereby forming different layers on the AM-EDMed surface [40]. The topmost layer is the extremely hard carbide layer, which is formed due to the reaction of carbon in the dielectric hydrocarbon fluid and the workpiece-electrode alloying elements. The recast and oxide film constituted the middle layers. The recast layer is produced because of resolidification of unflushed metallic debris in the craters. On the other hand, biocompatible, nanostructured, and nanoporous oxide layer is developed due to fusion of oxygen (foreign element) and the elemental constituents in the work material. The last layer is the heat affected zone (heated but nonmelted layer). This layer is formed due to heating and subsequent quenching during the EDM process. The characteristics of these layers mainly depend on the type of electrodes material, powder particles, dielectric fluid, and the setting of the machining parameters [151]. The schematic illustration of material migration mechanism and material deposition during AMEDM is displayed in Figure 17. In the first stage, a spark is generated through a powder suspended dielectric fluid. In this phase, the electrodes materials are eroded, forming a large crater. The detached electrodes particles, powder particles, and the carbon atoms migrated to the electrodes surfaces as shown in Figure 17(b). The final stage is shown in Figure 17(c); whereby all layers are completely formed, with no or shallow craters on the AM-EDMed surface. However, the tool-electrode size reduced due to erosion of the contact surface.

5.2. Formation and Influence of Recast Layer on EDMed Implant. Although a hard and adhesive recast layer is expected to enhance the corrosion and wear resistance of the metallic implant, a thick recast layer should be avoided or polished, to reduce the risk of the implant mechanical failure [149]. The recast layer thickness largely depends on the dielectric fluid type, the pulse-on time, and the powder concentration [11, 38]. EDM with kerosene as dielectric fluid produces thinner and porous recast layer as well as finer and harder surface when compared to water emulsion. It was also reported that the white layer thickness decreases with a decrease in pulse duration (electrical energy) [152]. In addition, an EDM automatic finishing setting and the addition of powder to the dielectric fluid reduced the formation of a recast layer $[11,153,154]$ as depicted in Figure 18.

\subsection{Biocompatible and Bioactive Oxide Layer Formation.} For long-term implantation of the biomedical implant, biocompatibility and bioactivity of such material are the key concern. A mechanically strong bonding between the implant and the body tissues which occurs due to biophysical and biochemical reactions is referred to as bioactive. Various biomaterials have different interfacial bonding time, strength, and bonding thickness [155]. Bioactive glass, glass ceramics, and hydroxyapatite are the most common and clinically 


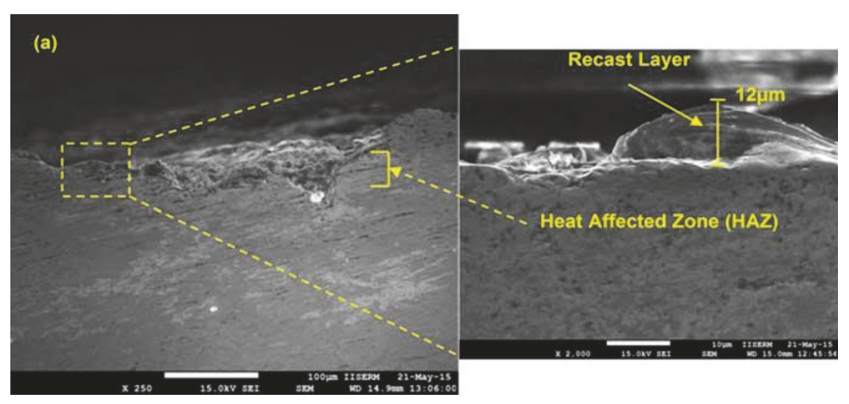

(a)

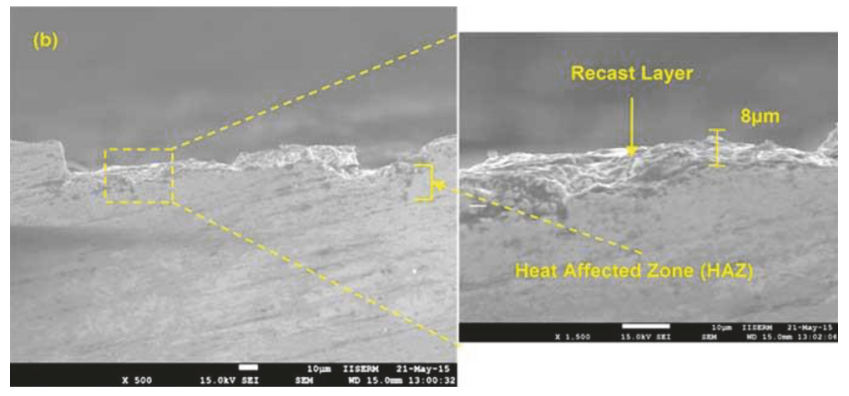

(b)

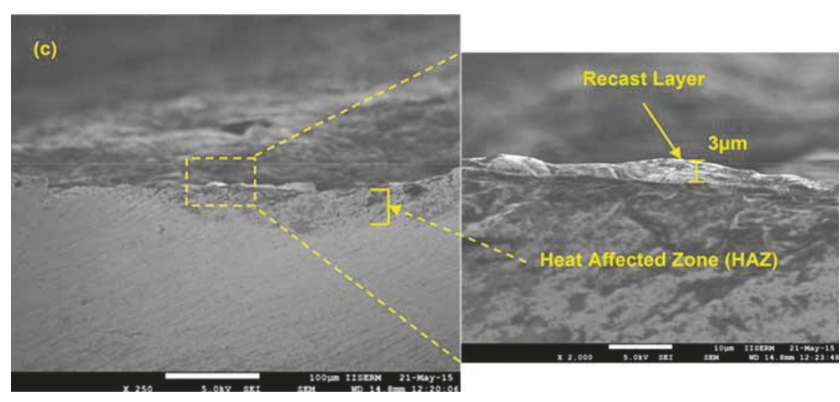

(c)

FIGURE 18: It shows a microscopic cross section of AM-EDMed $\beta$ phase Ti-alloy at Ip (5 A), Ton $(10 \mu \mathrm{s})$, and Si-powder concentration of (a) $0 \mathrm{~g} / \mathrm{L}$, (b) $2 \mathrm{~g} / \mathrm{L}$, and (c) $4 \mathrm{~g} / \mathrm{L}$ [11].

approved bioactive materials [156]. A good bioactive layer is expected to generate a bone-like structure and bone-like mechanical properties which will allow for tissue growth and attachment. Implant biocompatibility and bioactivity do depend on not only the material properties but also the implant manufacturing and coating techniques which the implant undergoes. AM-EDM is a novel technique which can be used to deposit a biocompatible and bioactive layer on the implant surface. One of the approaches of depositing these layers is by mixing the EDM dielectric fluid with a bioactive powder. Another way is to use a bioactive tool electrode. The last approach is to employ both powder and the tool electrode. A nanoporous and calcium-rich oxide layer is produced on Ti-6Al-4V surface when $0.1 \mathrm{Mol} / \mathrm{L}$ of calcium chloride aqueous solution was added to deionized water during sinking EDM [136]. This oxide surface was proved to have high hardness and reasonable biocompatibility, enough for biomedical applications, especially for bone and teeth. A SEM micrograph of EDMed Ti-6Al-4V surface with deposited

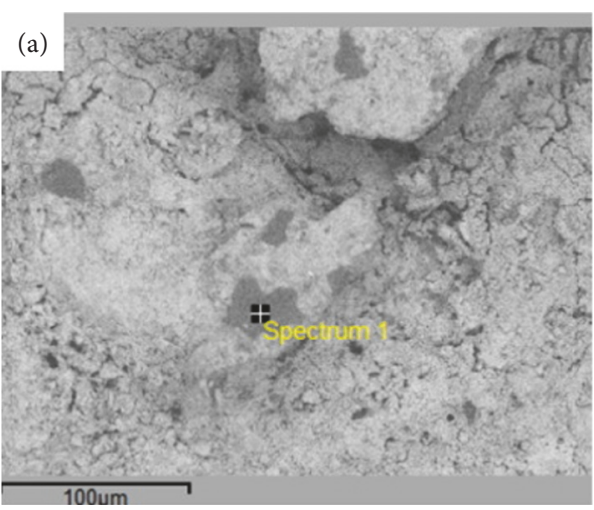

(a)

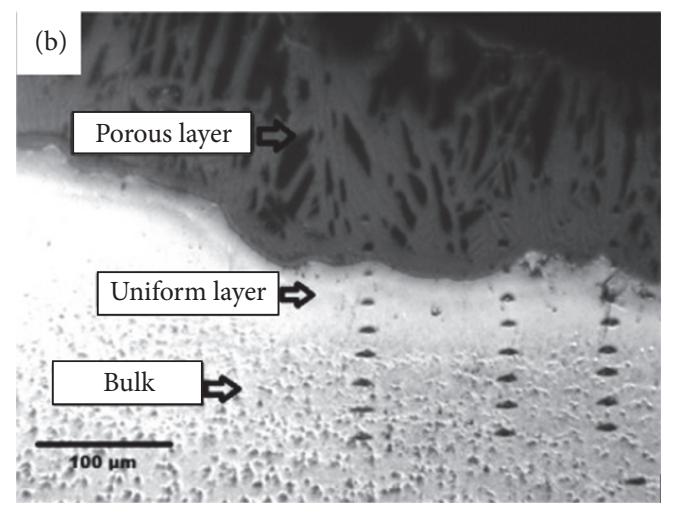

(b)

FIGURE 19: SEM micrograph: (a) Ti-6Al-4V after calcium deposition by AM-EDM; (b) uniformly distributed porous layers. Copyright @Elsevier, reproduced with permission from Elsevier [136].

calcium is shown in Figure 19(a) and a porous surface in Figure 19(b). A surface of Ti-6Al-4V treated via an EDM process by Strasky et al. [157] shows a substantially higher number of cells when compared with a commercial plasma spray coating technique as displayed in Figure 20. Thus, it can be stated that the substrate modified through AM-EDM produces exceptional substrate for the adhesion and growth of human bone compared to the alloy plasma sprayed. A similar research conducted by Yang et al. [158] revealed a high cells attachment and proliferation on EDMed samples when compared with the untreated samples. The in vitro cell response of the treated and untreated substrates is depicted in Figure 21. Another study by Otsuka et al. [159] revealed a great rise of the cell attachment on the EDMed surface while the cell proliferation remained restrained. However, the number of cells was found to be increased. Chen et al. [91] studied the surface modification of Fe-Al-Mn alloy through AM-EDM. The experimental results presented a nanostructured recast and oxide layers which greatly enhanced the biocompatibility and osteointegration of the machined alloy. A nanoporous $\mathrm{TiO}_{2}$ formed during EDM of titanium is believed to be responsible for the generation of bioactive and biocompatible layer on the machined sample [19]. A study on the EDM of $\beta$-Ti-alloy presented by Prakash et al. [160] revealed a 


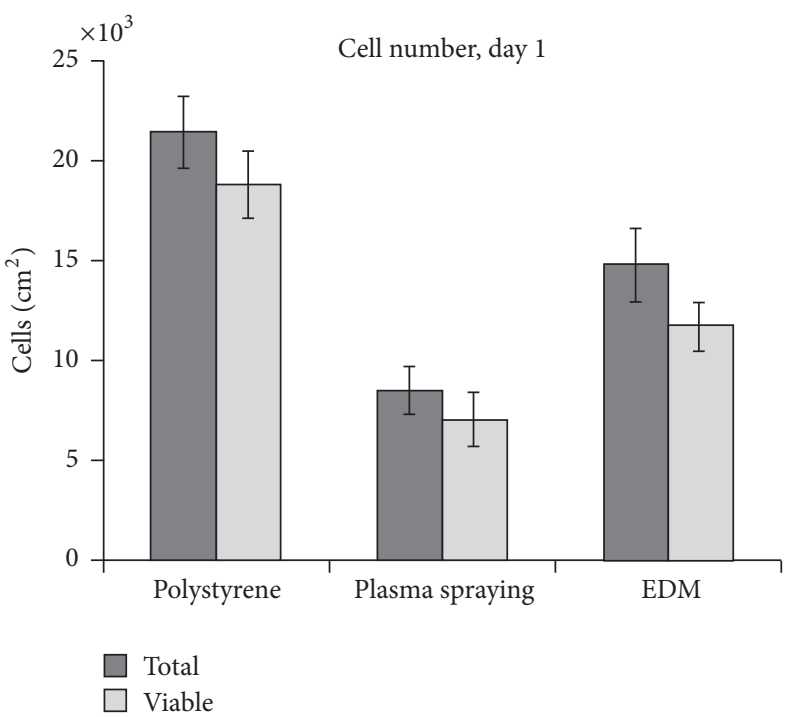

(a)

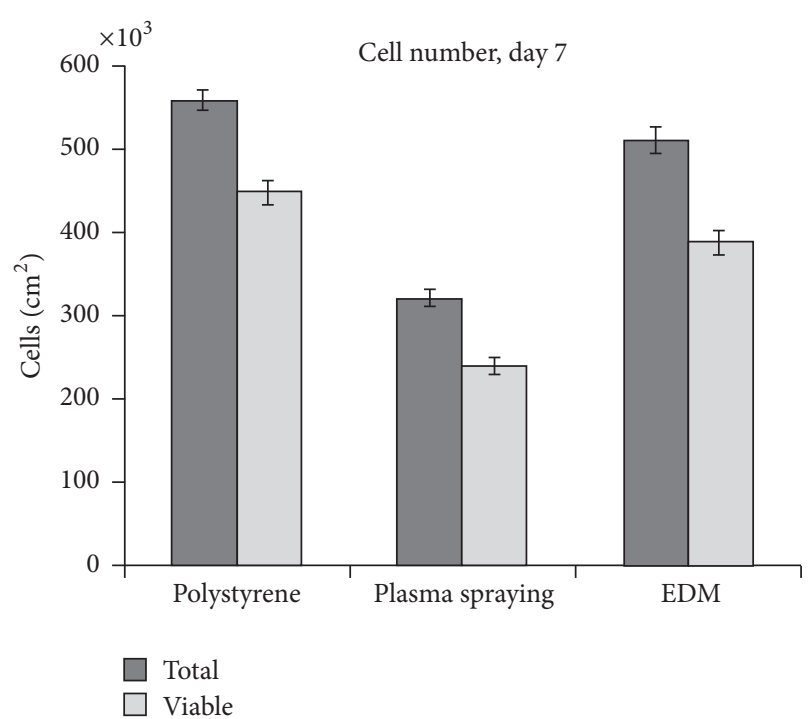

(b)

FIgURE 20: A quantity of human osteoblast-like cells for a Ti-6Al-4V alloy treated by plasma-spraying with $\mathrm{TiO}_{2}$ and $\mathrm{EDM}$ seeded on standardized cell culture polystyrene dishes for day 1 and day 7 [157].
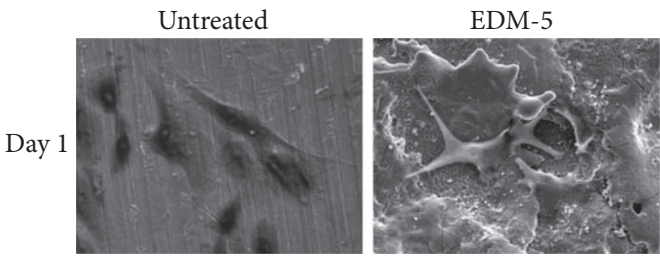

(a)

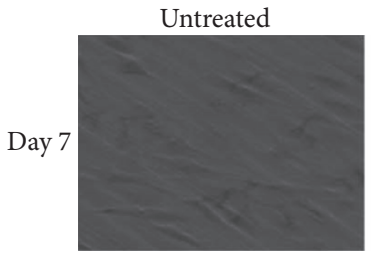

EDM-5

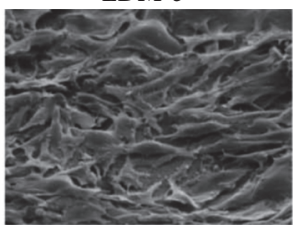

(b)

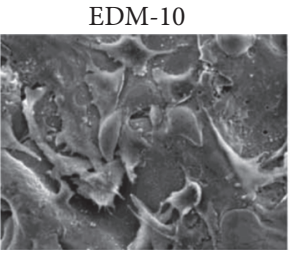

EDM-10

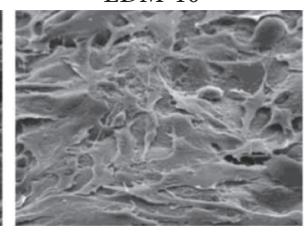

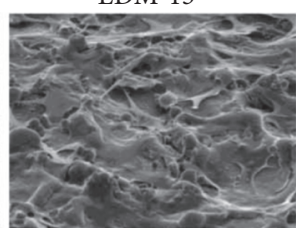

EDM-15

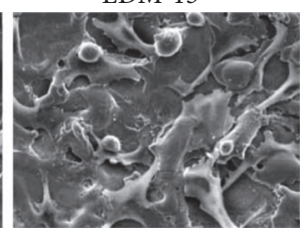

EDM-15

FIGURE 21: SEM micrograph of the in vitro MG-63 cells attachment and proliferation on the treated and untreated samples for (a) day 1 and (b) day $7[158]$.

higher cell growth and adhesion on the machined surface. In similar studies, carbide and oxide layers which enhance the biocompatibility of $\beta$-Ti-alloy were achieved when Sipowder was added to the EDM dielectric fluid [11]. It was also proven that the nanoporosities fabricated by PM-EDM process promote the cell growth and adhesion [161, 162]. A nanofinished, bioactive, and biocompatible surface was achieved during PM-EDM of Ti-alloy [163]. The XRD patterns showing the titanium oxide and nitride layer deposition after electrodischarge coating are elaborated in Figure 22.

5.4. Hard and Nanoporous Carbide Layer Formation. The quest for long-term capability of orthopedic or dental implant after implantation remains indispensable. Several reports confirm the premature failure of the implanted hard tissue such as bone and teeth as elaborated in Section 3.1. Poor corrosion and wear characteristics of the implant material like stainless steel, $\mathrm{Co}-\mathrm{Cr}$, and $\mathrm{Ti}$ alloys are considered as the root cause of this problem [60-63, 66]. However, formation or deposition of hard carbide layer on the implant surface remained the key remedy to this issue. A carbide film can be generated on the substrate surface by using carbide containing tool electrode, powders, or dielectric fluid. The carbon released by these substances can easily react to the alloying elements in the workpiece-electrode material during AM-EDM process. Algodi et al. [164] investigated the deposition of TiC-Fe layer on the stainless steel using $\mathrm{TiC}$ tool-electrode. The results revealed a high deposition of TiC carbide film on the EDMed surface. This carbide coated surface was characterized by a high but variable hardness 


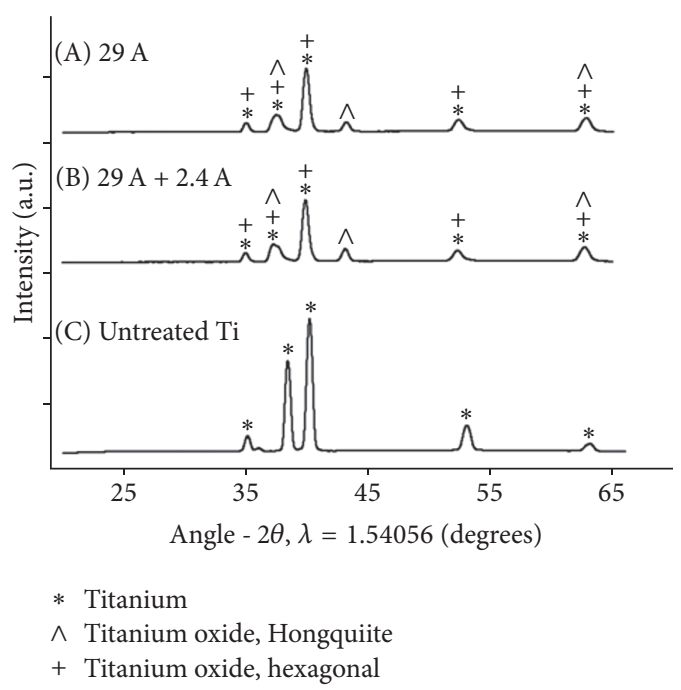

(a)

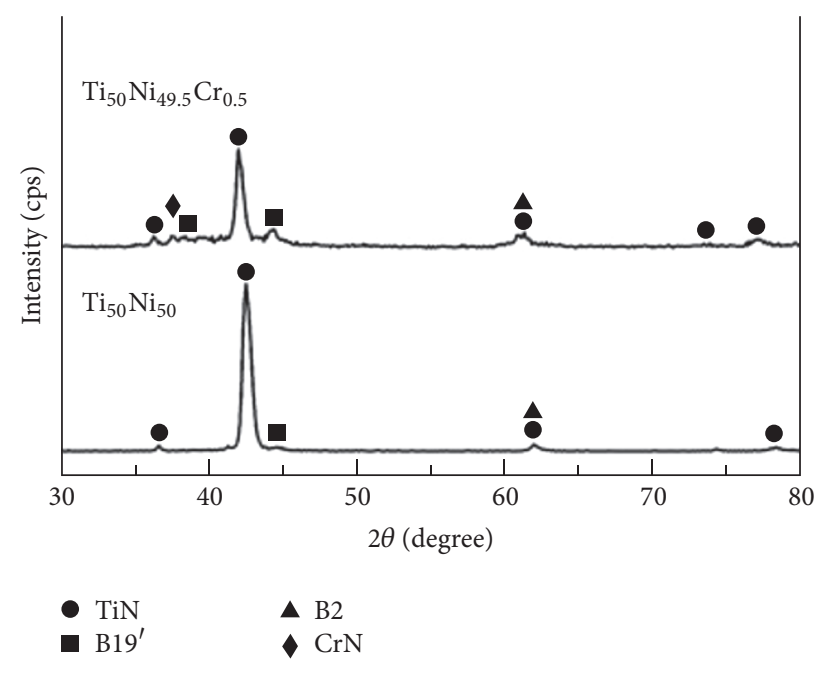

(b)

FIGURE 22: It depicts XRD patterns showing titanium oxide and nitride layers deposition after electrodischarge coating. Copyright @Elsevier, reproduced with permission from Elsevier [87, 149].

which may be related to variation of the carbide content on the modified surface. A study presented by Prakash et al. [165] confirmed the production of an extremely hard $\mathrm{TiC}$ layer with good wear characteristics during EDM of $\beta-\mathrm{Ti}$ for orthopedic use. The deposition of titanium carbide on the carbon steel work material using graphite powder was successfully achieved [166]. It is found that the added powder not only enhanced the uniformity of the coated layer and the microcracks but also contributed more carbon in the dielectric fluid. In addition, the hardness and wear resistance of the workpiece-electrode material were greatly enhanced. Li et al. [167] observed the Ti-6Al-4V EDMed surface behavior by mixing silicon carbide abrasives with dielectric fluid. The results revealed the formation of carbide film, which is characterized by more than twofold rise in hardness and greatly improves wear resistance. Clear boundary and fine finishing are also noticed. In similar studies, Kuriachen and Mathew [168] reported the formation of hard silicon and tungsten carbide layers on the machined $\mathrm{Ti}-6 \mathrm{Al}-4 \mathrm{~V}$ when $\mathrm{SiC}$ powder was mixed with the dielectric fluids using tungsten carbide tool-electrode. Table 6 critically reviews the recent studies for material deposition of metallic implant through the AM-EDM process.

\section{Challenges and Future Studies}

Besides various potentialities of AM-EDM in manufacturing industries and the medical field, there are several issues which are yet to be solved to qualify the application of the EDM process at the clinical stage. These are summarized as follows:

(i) It is very difficult to control and measure the actual thickness of the layer deposited by AM-EDM. An extensive study in this direction will be helpful.

(ii) It is quite challenging to set an optimum powder concentration for achieving a required coated layer size on the implant surface. Thus, there is a need for more researches that will focus on setting the optimum powder concentration for surface coating through AM-EDM.

(iii) The mechanism of material deposition during AMEDM is not clearly understood, owing to the complexity of the process. However, future studies need to concentrate on material deposition monitoring during the machining process.

(iv) There is a great challenge in controlling the uniformity of the deposited layer on the AM-EDMed implant surface, which is supposed to provide sufficient and uniform implant-bone bonding.

(v) AM-EDM parameter settings depend on the material type. Thus, setting optimum parameters that will suit all material combinations remained challenging.

(vi) Materials are melted and subsequently quenched during AM-EDM. Thus, there is a considerable risk of transforming the material structure into different phases. This might affect the initial performance and mechanical properties of the substrate materials. Thus, extensive studies are required in this segment.

\section{Summary}

For the long-term performance of an implant, a fast bonetissue interaction is believed to be dependent on surface characteristic and properties of the deposited layer by the surface modification technique. It has been found that the implant with HA coating has enhanced the bioactivity and promotes the bone-tissue growth and osseointegration at a faster rate. Accordingly, numerous surface treatment/modification techniques like chemical vapor deposition (CVD), physical vapor deposition (PVD), iodization, and laser deposition 
TABLE 6: Critical review of recent development of material deposition and surface treatment of metallic implant through AM-EDM.

\begin{tabular}{|c|c|c|c|c|}
\hline $\begin{array}{l}\text { Electrodes } \\
\text { combination }\end{array}$ & Powder type/conc. & Deposited layers & Findings & Refs. \\
\hline Grade IV Ti/Ti & $\mathrm{Ti} / 3 \& 6 \mathrm{~g} / \mathrm{L}$ & $\begin{array}{l}\text { (i) } \mathrm{TiO} \\
\text { (ii) Recast layers }\end{array}$ & $\begin{array}{l}\text { (i) With } 3 \mathrm{~g} / \mathrm{l} \text { microcracks observed and disappeared } \\
\text { when using } 6 \mathrm{~g} / \mathrm{l} \text { of Ti } \\
\text { (ii) Recast layer thickness increases with increase in } \\
\text { current duration and Ti powder concentration } \\
\text { (iii) Hydrophilic surface good for dental implant was } \\
\text { observed }\end{array}$ & {$[86]$} \\
\hline Grade II Ti/Ti & - & (i) $\mathrm{TiO}$ & $\begin{array}{l}\text { (i) Dual surface topography with micron and } \\
\text { submicron topographies sufficient for orthopedic and } \\
\text { dental applications }\end{array}$ & {$[87]$} \\
\hline AISI D2 steel/Ti & $\mathrm{Ti} / 2 \mathrm{~g} / \mathrm{L}$ & (i) $\mathrm{TiC}$ & $\begin{array}{l}\text { (i) Significant Improvement in surface roughness } \\
\text { (ii) Shallow craters and craters diminishes } \\
\text { (iii) Ti atoms higher in the cracks area }\end{array}$ & {$[88]$} \\
\hline $\begin{array}{l}\beta-\mathrm{Ti} \text { alloy } \\
(\mathrm{Ti}-\mathrm{Na}-\mathrm{Ta}-\mathrm{Zr}) / \mathrm{Cp}-\mathrm{Ti}\end{array}$ & $\mathrm{Si} / 0,2,4,6 \& 8 \mathrm{~g} / \mathrm{L}$ & $\begin{array}{l}\text { (i) Bioceramic oxides } \\
\text { (ii) Carbide phases }\end{array}$ & $\begin{array}{l}\text { (i) EDMed surface hardness twice the pure sample } \\
\text { (ii) } 4 \mathrm{~g} / \mathrm{L} \text { of Si powder produces thin recast layer } \\
\text { (iii) A nanoporous, bioactive and biocompatible surface } \\
\text { achieved }\end{array}$ & {$[11]$} \\
\hline Ti-6Al-4V/Ti & $\begin{array}{l}\mathrm{HA} / 5,10,15 \& \\
20 \mathrm{~g} / \mathrm{L}\end{array}$ & (i) $\mathrm{HA}$ & $\begin{array}{l}\text { (i) AM-EDM can be used as alternative for HA reach } \\
\text { layer deposition on the substrate } \\
\text { (ii) AM-EDM produces biocompatible coating for } \\
\text { medical applications }\end{array}$ & {$[89]$} \\
\hline $\mathrm{Ti}-6 \mathrm{Al}-4 \mathrm{~V} / \mathrm{Cu}$ & $\begin{array}{l}\text { Surfactant + } \\
\text { Graphite }(\mathrm{Gr}) \\
\text { 1-20/gL }\end{array}$ & (i) Recast layer & $\begin{array}{l}\text { (i) RLT layer reduced with } 6 \mathrm{~g} / \mathrm{L} \text { of surfactant which } \\
\text { becomes evenly distributed with } 10 \mathrm{~g} / \mathrm{L} \text { of } \mathrm{Gr} \\
\text { (ii) Less microcracks were also observed } \\
\text { (iii) Surfactant inhibit a powerful material migration }\end{array}$ & {$[38]$} \\
\hline Ti-6Al-4V/Ti & HA & (i) $\mathrm{HA}$ & $\begin{array}{l}\text { (i) Moderate pulse-on current and pulse-on duration } \\
\text { are possible settings that will produce material } \\
\text { deposition }\end{array}$ & {$[90]$} \\
\hline Grade IV Ti/Cu & - & $\begin{array}{l}\text { (i) } \mathrm{TiO}_{2} \\
\text { (ii) } \mathrm{Nano} \mathrm{TiH}\end{array}$ & $\begin{array}{l}\text { (i) A nanoporous, nanostructured and bioactive } \mathrm{TiO}_{2} \\
\text { layer with short duration } \\
\text { (ii) Improved biocompatibility was achieved }\end{array}$ & {$[19]$} \\
\hline $\mathrm{Fe}-\mathrm{Al}-\mathrm{Mn} / \mathrm{Cu}$ & - & $\begin{array}{l}\text { (i) Recast layer } \\
\text { (ii) Oxide layer } \\
\text { (iii) k-carbide phase }\end{array}$ & $\begin{array}{l}\text { (i) Nanostructured recast layer was formed } \\
\text { (ii) Increased biocompatibility }\end{array}$ & {$[91]$} \\
\hline WC90-Co10/Cu & $\mathrm{Ti}$ & (i) $\mathrm{TiC}$ & (i) Improved hardness with reduced microcracks & {$[92]$} \\
\hline
\end{tabular}

were used to improve the implant stability. However, typically, the coating techniques used for the surface treatment have a few key problems, (i) very thin coating layer and (ii) weak adhesion and bond strength with the substrate, which can deteriorate after some time due to acidic nature of body fluid, causing the implant failure. In contrast to this, the electric discharge machining (EDM) shows better potential for surface treatment of metallic implants. The role of EDM process for surface modification of biomaterials is still at the experimental stage. A few number of research studies have been reported by taking hydroxyapatite powder mixed-EDM as surface modification process for biomaterials; superior biocompatible surface characteristics have been reported and capability of formation of biocompatible nanoporous surface has been reported. This paper reviewed the recent development of AM-EDM and its application as a potential technique for the surface treatment of orthopedic and dental implants. Deposition of bioactive and biocompatible layers on the implant surface through AM-EDM process depends on various factors which include appropriate selection of electrodes, powder, dielectric fluid, and optimum EDM parameters setting. In addition, AM-EDM can be used to generate a mirror-like finishing and extremely hard surface on the metallic implant surface. However, the powder, dielectric, and electrodes material type are found to have great influence on the thickness and quality of the coated surface. Despite this, there are a gap and the urgent need to study the effect of various input independent parameters of AM-EDM on the machining of magnesium implant, metallic glass, and new $\beta$-Ti materials.

\section{Conflicts of Interest}

The authors declare that they have no conflicts of interest.

\section{Acknowledgments}

Special thanks and appreciation are due to the Biomedical Technology, MOR, for providing Grant 0153BG-001 and 
Centre for Graduate Studies, UTP, for financing this research. The authors also acknowledge the support by Universiti Teknologi PETRONAS (UTP) for providing the necessary tools for the conduct of this research.

\section{References}

[1] V. García Navas, I. Ferreres, J. A. Marañón, C. Garcia-Rosales, and J. Gil Sevillano, "Electro-discharge machining (EDM) versus hard turning and grinding-Comparison of residual stresses and surface integrity generated in AISI O1 tool steel," Journal of Materials Processing Technology, vol. 195, no. 1-3, pp. 186-194, 2008.

[2] S. Clijsters, K. Liu, D. Reynaerts, and B. Lauwers, "EDM technology and strategy development for the manufacturing of complex parts in SiSiC," Journal of Materials Processing Technology, vol. 210, no. 4, pp. 631-641, 2010.

[3] A. A. Aliyu, H. Musa, and J. M. Rohani, "Parametric study of powder mixed electrical discharge machining and mathematical modeling of SiSiC using copper electrode," Advanced Materials Research, vol. 845, pp. 878-882, 2014.

[4] S. Barman, Vijay, Nagahanumaiah, and A. B. Puri, "Surface Texture and Elemental Characterization of High Aspect Ratio Blind Micro Holes on Different Materials in Micro EDM," Procedia Materials Science, vol. 6, pp. 304-309, 2014.

[5] A. M. Nanimina, A. M. Abdul Rani, and T. L. Ginta, "Assessment of powder mixed EDM: A review," in Proceedings of the 4th International Conference on Production, Energy and Reliability, ICPER 2014, June 2014.

[6] Y. Pachaury and P. Tandon, "An overview of electric discharge machining of ceramics and ceramic based composites," Journal of Manufacturing Processes, vol. 25, pp. 369-390, 2017.

[7] F. L. Amorim and W. L. Weingaertner, "Die-sinking electrical discharge machining of a high-strength copper-based alloy for injection molds," Journal of the Brazilian Society of Mechanical Sciences and Engineering, vol. 26, no. 2, pp. 137-144, 2004.

[8] I. Cabanes, E. Portillo, M. Marcos, and J. A. Sánchez, "An industrial application for on-line detection of instability and wire breakage in wire EDM," Journal of Materials Processing Technology, vol. 195, no. 1-3, pp. 101-109, 2008.

[9] M. A. Volosova, A. A. Okunkova, D. E. Povolotskiy, and P. A. Podrabinnik, "Study of electrical discharge machining for the parts of nuclear industry usage," Mechanics \& Industry, vol. 16, no. 7, p. 706, 2015.

[10] C. Prakash, H. K. Kansal, B. S. Pabla, S. Puri, and A. Aggarwal, "Electric discharge machining - A potential choice for surface modification of metallic implants for orthopedic applications: A review," Proceedings of the Institution of Mechanical Engineers, Part B: Journal of Engineering Manufacture, vol. 230, no. 2, pp. 331-353, 2016.

[11] C. Prakash, H. K. Kansal, B. S. Pabla, and S. Puri, "Experimental investigations in powder mixed electric discharge machining of Ti-35Nb-7Ta- $5 \mathrm{Zr} \beta$-titanium alloy," Materials and Manufacturing Processes, vol. 32, no. 3, pp. 274-285, 2017.

[12] A. M. Abdul-Rani, A. M. Nanimina, T. L. Ginta, and M. A. Razak, "Machined Surface Quality in Nano Aluminum Mixed Electrical Discharge Machining," Procedia Manufacturing, vol. 7, pp. 510-517, 2017.

[13] F. Iacono, C. Pirani, L. Generali et al., "Wear analysis and cyclic fatigue resistance of electro discharge machined NiTi rotary instruments," Giornale Italiano di Endodonzia, vol. 30, no. 1, pp. 64-68, 2016.
[14] A. Ntasi, W. D. Mueller, G. Eliades, and S. Zinelis, "The effect of Electro Discharge Machining (EDM) on the corrosion resistance of dental alloys," Dental Materials, vol. 26, no. 12, pp. e237-e245, 2010.

[15] C. Prakash, H. K. Kansal, B. S. Pabla, and S. Puri, "To optimize the surface roughness and microhardness of $\beta$-Ti alloy in PMEDM process using Non-dominated Sorting Genetic Algorithm-II," in Proceedings of the 2nd International Conference on Recent Advances in Engineering and Computational Sciences, RAECS 2015, Chandigarh, India, December 2015.

[16] M. T. Mohammed, Z. A. Khan, and A. N. Siddiquee, "Surface Modifications of Titanium Materials for developing Corrosion Behavior in Human Body Environment: A Review," Procedia Materials Science, vol. 6, pp. 1610-1618, 2014.

[17] A. M. Abdul-Rani, M. A. Razak, G. Littlefair, I. Gibson, and A. M. Nanimina, "Improving EDM Process on AZ31 Magnesium Alloy towards Sustainable Biodegradable Implant Manufacturing," Procedia Manufacturing, vol. 7, pp. 504-509, 2017.

[18] M. A. Razak, A. M. Abdul-Rani, T. V. V. L. N. Rao, S. R. Pedapati, and S. Kamal, "Electrical Discharge Machining on Biodegradable AZ31 Magnesium Alloy Using Taguchi Method," Procedia Engineering, vol. 148, pp. 916-922, 2016.

[19] P.-W. Peng, K.-L. Ou, H.-C. Lin, Y.-N. Pan, and C.-H. Wang, "Effect of electrical-discharging on formation of nanoporous biocompatible layer on titanium," Journal of Alloys and Compounds, vol. 492, no. 1-2, pp. 625-630, 2010.

[20] R. Zou, Z. Yu, W. Li, M. Guo, and J. Li, "Influence of porous structure on the machining performance of micro EDM," Journal of Materials Processing Technology, vol. 232, pp. 43-51, 2016.

[21] H. Hermawan, D. Ramdan, and J. R. Djuansjah, Metals for Biomedical Applications, INTECH, 2011.

[22] M. Niinomi, "Mechanical biocompatibilities of titanium alloys for biomedical applications," Journal of the Mechanical Behavior of Biomedical Materials, vol. 1, no. 1, pp. 30-42, 2008.

[23] M. Geetha, A. K. Singh, R. Asokamani, and A. K. Gogia, "Ti based biomaterials, the ultimate choice for orthopaedic implants-a review," Progress in Materials Science, vol. 54, no. 3, pp. 397-425, 2009.

[24] C. K. Seal, K. Vince, and M. A. Hodgson, "Biodegradable surgical implants based on magnesium alloys - A review of current research," in Proceedings of the IOP Conference Series: Materials Science and Engineering, IOP Publishing, 2009.

[25] F. Witte, "The history of biodegradable magnesium implants: a review," Acta Biomaterialia, vol. 6, no. 5, pp. 1680-1692, 2010.

[26] N. T. Kirkland, N. Birbilis, and M. P. Staiger, "Assessing the corrosion of biodegradable magnesium implants: A critical review of current methodologies and their limitations," Acta Biomaterialia, vol. 8, no. 3, pp. 925-936, 2012.

[27] Y. Chen, Z. Xu, C. Smith, and J. Sankar, "Recent advances on the development of magnesium alloys for biodegradable implants," Acta Biomaterialia, vol. 10, no. 11, pp. 4561-4573, 2014.

[28] H. F. Li and Y. F. Zheng, "Recent advances in bulk metallic glasses for biomedical applications," Acta Biomaterialia, vol. 36, pp. 1-20, 2016.

[29] Y. Sun, Y. Huang, H. Fan et al., "In vitro and in vivo biocompatibility of an Ag-bearing Zr-based bulk metallic glass for potential medical use," Journal of Non-Crystalline Solids, vol. 419, pp. 8291, 2015.

[30] J. F. Löffler, “Bulk metallic glasses," Intermetallics, vol. 11, no. 6, pp. 529-540, 2003. 
[31] D. C. Hofmann, "Bulk Metallic Glasses and Their Composites: A Brief History of Diverging Fields," Journal of Materials, vol. 2013, Article ID 517904, 8 pages, 2013.

[32] W. Ge, B. Li, E. Axinte, Z. Zhang, C. Shang, and Y. Wang, "Crystallization and Corrosion Resistance in Different Aqueous Solutions of Zr50.7Ni28Cu9Al12.3 Amorphous Alloy and Its Crystallization Counterparts," JOM, vol. 69, no. 4, pp. 776-783, 2017.

[33] J. C. E. Odekerken, T. J. M. Welting, J. J. C. Arts, G. H. I. M. Walenkamp, and P. J. Emans, "Modern orthopaedic implant coatings - their pro's, con's and evaluation method," in Modern Surface Engineering Treatments, pp. 45-73, InTech, New York, USA, 2013.

[34] R. I. M. Asri, W. S. W. Harun, M. A. Hassan, S. A. C. Ghani, and Z. Buyong, "A review of hydroxyapatite-based coating techniques: Sol-gel and electrochemical depositions on biocompatible metals," Journal of the Mechanical Behavior of Biomedical Materials, vol. 57, pp. 95-108, 2016.

[35] S. V. Dorozhkin, "Calcium orthophosphate deposits: Preparation, properties and biomedical applications," Materials Science and Engineering C, vol. 55, pp. 272-326, 2015.

[36] Y. Zhang, Y. Liu, Y. Shen, R. Ji, Z. Li, and C. Zheng, "Investigation on the influence of the dielectrics on the material removal characteristics of EDM," Journal of Materials Processing Technology, vol. 214, no. 5, pp. 1052-1061, 2014.

[37] F. Klocke, M. Schwade, A. Klink, and A. Kopp, "EDM machining capabilities of magnesium $(\mathrm{Mg})$ alloy WE43 for medical applications," Procedia Engineering, vol. 19, pp. 190-195, 2011.

[38] M. Kolli and A. Kumar, "Surfactant and graphite powderassisted electrical discharge machining of titanium alloy," Proceedings of the Institution of Mechanical Engineers, Part B: Journal of Engineering Manufacture, vol. 231, no. 4, pp. 641-657, 2017.

[39] A. Batish, A. Bhattacharya, V. K. Singla, and G. Singh, "Study of material transfer mechanism in die steels using powder mixed electric discharge machining," Materials and Manufacturing Processes, vol. 27, no. 4, pp. 449-456, 2012.

[40] J. S. Soni and G. Chakraverti, "Experimental investigation on migration of material during EDM of die steel (T215 Cr12)," Journal of Materials Processing Technology, vol. 56, no. 1-4, pp. 439-451, 1996.

[41] X. Liu, P. K. Chu, and C. Ding, "Surface modification of titanium, titanium alloys, and related materials for biomedical applications," Materials Science and Engineering R: Reports, vol. 47, no. 3-4, pp. 49-121, 2004.

[42] Q. Chen and G. A. Thouas, "Metallic implant biomaterials," Materials Science and Engineering R: Reports, vol. 87, pp. 1-57, 2014.

[43] X. Wang, S. Xu, S. Zhou et al., "Topological design and additive manufacturing of porous metals for bone scaffolds and orthopaedic implants: a review," Biomaterials, vol. 83, no. 6, pp. 127-141, 2016.

[44] M. J. Mirzaali, J. J. Schwiedrzik, S. Thaiwichai et al., "Mechanical properties of cortical bone and their relationships with age, gender, composition and microindentation properties in the elderly," Bone, vol. 93, pp. 196-211, 2016.

[45] F. Libonati and L. Vergani, "Understanding the structureproperty relationship in cortical bone to design a biomimetic composite," Composite Structures, vol. 139, pp. 188-198, 2016.

[46] J.-Y. Rho, L. Kuhn-Spearing, and P. Zioupos, "Mechanical properties and the hierarchical structure of bone," Medical Engineering \& Physics, vol. 20, no. 2, pp. 92-102, 1998.
[47] J. E. Lemons, "Dental implant biomaterials.," The Journal of the American Dental Association, vol. 121, no. 6, pp. 716-719, 1990.

[48] D. F. Williams, "On the nature of biomaterials," Biomaterials, vol. 30, no. 30, pp. 5897-5909, 2009.

[49] A. King and J. R. A. Phillips, "Total hip and knee replacement surgery," Surgery (United Kingdom), vol. 34, no. 9, pp. 468-474, 2016.

[50] C. J. DeFrances, C. A. Lucas, V. C. Buie, and A. Golosinskiy, "2006 national hospital discharge survey," National Health Statistics Reports, vol. 5, pp. 1-20, 2008.

[51] M. M. Dewidar, K. A. Khalil, and J. K. Lim, "Processing and mechanical properties of porous 316L stainless steel for biomedical applications," Transactions of Nonferrous Metals Society of China (English Edition), vol. 17, no. 3, pp. 468-473, 2007.

[52] Y. Oshida, E. B. Tuna, O. Aktören, and K. Gençay, "Dental implant systems," International Journal of Molecular Sciences, vol. 11, no. 4, pp. 1580-1678, 2010.

[53] K. L. Ong, B. M. Yun, and J. B. White, "New biomaterials for orthopedic implants," Orthopedic Research and Reviews, vol. 7, pp. 107-130, 2015.

[54] S.-H. Lee, N. Nomura, and A. Chiba, "Significant improvement in mechanical properties of biomedical Co-Cr-Mo alloys with combination of $\mathrm{N}$ addition and Cr-enrichment," Materials Transactions, vol. 49, no. 2, pp. 260-264, 2008.

[55] K. Yang and Y. Ren, "Nickel-free austenitic stainless steels for medical applications," Science and Technology of Advanced Materials, vol. 11, no. 1, p. 014105, 2016.

[56] E. Axinte, A. Bofu, Y. Wang et al., "An overview on the conventional and nonconventional methods for manufacturing the metallic glasses," MATEC Web of Conferences, vol. 112, p. 03003, 2017.

[57] M. H. Fathi, M. Salehi, A. Saatchi, V. Mortazavi, and S. B. Moosavi, "In vitro corrosion behavior of bioceramic, metallic, and bioceramic-metallic coated stainless steel dental implants," Dental Materials, vol. 19, no. 3, pp. 188-198, 2003.

[58] C. A. Schuh, T. C. Hufnagel, and U. Ramamurty, "Mechanical behavior of amorphous alloys," Acta Materialia, vol. 55, no. 12, pp. 4067-4109, 2007.

[59] Y. Liu, G. Wang, H. Li, S. Pang, K. Chen, and T. Zhang, "Ti-Cu-Zr-Fe-Sn-Si-Sc bulk metallic glasses with good mechanical properties for biomedical applications," Journal of Alloys and Compounds, vol. 679, pp. 341-349, 2016.

[60] B. M. Stronach, M. D. Roach, and K. R. St. John, "Failure of Emperion modular femoral stem with implant analysis," Arthroplasty Today, vol. 2, no. 1, pp. 11-14, 2016.

[61] L. Guerra-Fuentes, E. Garcia-Sanchez, A. Juarez-Hernandez, and M. A. L. Hernandez-Rodriguez, "Failure analysis in 316L stainless steel supracondylar blade plate," Engineering Failure Analysis, vol. 57, pp. 243-247, 2015.

[62] M. A. L. Hernandez-Rodriguez, G. R. Contreras-Hernandez, A. Juarez-Hernandez, B. Beltran-Ramirez, and E. Garcia-Sanchez, "Failure analysis in a dental implant," Engineering Failure Analysis, vol. 57, pp. 236-242, 2015.

[63] B. Gervais, A. Vadean, M. Raison, and M. Brochu, "Failure analysis of a 316L stainless steel femoral orthopedic implant," Case Studies in Engineering Failure Analysis, vol. 5-6, pp. 30-38, 2016.

[64] C. Kanchanomai, V. Phiphobmongkol, and P. Muanjan, "Fatigue failure of an orthopedic implant - A locking compression plate," Engineering Failure Analysis, vol. 15, no. 5, pp. 521-530, 2008. 
[65] H. Amel-Farzad, M. T. Peivandi, and S. M. R. Yusof-Sani, "Inbody corrosion fatigue failure of a stainless steel orthopaedic implant with a rare collection of different damage mechanisms," Engineering Failure Analysis, vol. 14, no. 7, pp. 1205-1217, 2007.

[66] J. Marcomini, C. A. R. P. Baptista, J. P. Pascon, R. L. Teixeira, and F. P. Reis, "Investigation of a fatigue failure in a stainless steel femoral plate," Journal of the Mechanical Behavior of Biomedical Materials, vol. 38, pp. 52-58, 2014.

[67] Y. Yang, K.-H. Kim, and J. L. Ong, "A review on calcium phosphate coatings produced using a sputtering process-an alternative to plasma spraying," Biomaterials, vol. 26, no. 3, pp. 327-337, 2005.

[68] H.-W. Kim, H.-E. Kim, and J. C. Knowles, "Fluor-hydroxyapatite sol-gel coating on titanium substrate for hard tissue implants," Biomaterials, vol. 25, no. 17, pp. 3351-3358, 2004.

[69] M. H. Fathi and A. Doost Mohammadi, "Preparation and characterization of sol-gel bioactive glass coating for improvement of biocompatibility of human body implant," Materials Science and Engineering A, vol. 474, no. 1-2, pp. 128-133, 2008.

[70] B. R. Gligorijević, M. Vilotijević, M. Šćepanović, D. Vidović, and N. A. Radović, "Surface structural heterogeneity of high power plasma-sprayed hydroxyapatite coatings," Journal of Alloys and Compounds, vol. 687, pp. 421-430, 2016.

[71] H. Xu, X. Geng, G. Liu et al., "Deposition, nanostructure and phase composition of suspension plasma-sprayed hydroxyapatite coatings," Ceramics International, vol. 42, no. 7, pp. 86848690, 2016.

[72] Z. Ur Rahman, I. Shabib, and W. Haider, "Surface characterization and cytotoxicity analysis of plasma sprayed coatings on titanium alloys," Materials Science and Engineering: $C$, vol. 67, pp. 675-683, 2016.

[73] O. Blind, L. H. Klein, B. Dailey, and L. Jordan, "Characterization of hydroxyapatite films obtained by pulsed-laser deposition on Ti and Ti-6AL-4v substrates," Dental Materials, vol. 21, no. 11, pp. 1017-1024, 2005.

[74] Q. Bao, C. Chen, D. Wang, Q. Ji, and T. Lei, "Pulsed laser deposition and its current research status in preparing hydroxyapatite thin films," Applied Surface Science, vol. 252, no. 5, pp. 15381544, 2005.

[75] C. F. Koch, S. Johnson, D. Kumar et al., "Pulsed laser deposition of hydroxyapatite thin films," Materials Science and Engineering C, vol. 27, no. 3, pp. 484-494, 2007.

[76] G. P. Dinda, J. Shin, and J. Mazumder, "Pulsed laser deposition of hydroxyapatite thin films on Ti-6Al-4V: Effect of heat treatment on structure and properties," Acta Biomaterialia, vol. 5, no. 5, pp. 1821-1830, 2009.

[77] J. Huang, S. N. Jayasinghe, S. M. Best et al., "Novel deposition of nano-sized silicon substituted hydroxyapatite by electrostatic spraying," Journal of Materials Science: Materials in Medicine, vol. 16, no. 12, pp. 1137-1142, 2005.

[78] M. C. Siebers, X. F. Walboomers, S. C. G. Leeuwenburgh, J. G. C. Wolke, and J. A. Jansen, "Electrostatic spray deposition (ESD) of calcium phosphate coatings, an in vitro study with osteoblastlike cells," Biomaterials, vol. 25, no. 11, pp. 2019-2027, 2004.

[79] S. C. G. Leeuwenburgh, M. C. Heine, J. G. C. Wolke, S. E. Pratsinis, J. Schoonman, and J. A. Jansen, "Morphology of calcium phosphate coatings for biomedical applications deposited using Electrostatic Spray Deposition," Thin Solid Films, vol. 503, no. 1-2, pp. 69-78, 2006.
[80] A. Stoch, A. Brozek, G. Kmita, J. Stoch, W. Jastrz, and A. Rakowska, "Electrophoretic coating of hydroxyapatite on titanium implants," Journal of Molecular Structure, vol. 596, no. 1-3, pp. 191-200, 2001.

[81] D. Stojanovic, B. Jokic, D. Veljovic, R. Petrovic, P. S. Uskokovic, and D. Janackovic, "Bioactive glass-apatite composite coating for titanium implant synthesized by electrophoretic deposition," Journal of the European Ceramic Society, vol. 27, no. 2-3, pp. 1595-1599, 2007.

[82] C. T. Kwok, P. K. Wong, F. T. Cheng, and H. C. Man, "Characterization and corrosion behavior of hydroxyapatite coatings on Ti6Al4V fabricated by electrophoretic deposition," Applied Surface Science, vol. 255, no. 13-14, pp. 6736-6744, 2009.

[83] J. Li, H. Liao, and L. Hermansson, "Sintering of partiallystabilized zirconia and partially-stabilized zirconiahydroxyapatite composites by hot isostatic pressing and pressureless sintering," Biomaterials, vol. 17, no. 18, pp. 1787$1790,1996$.

[84] T. Onoki, K. Hosoi, and T. Hashida, "New technique for bonding hydroxyapatite ceramics and titanium by the hydrothermal hot-pressing method," Scripta Materialia, vol. 52, no. 8, pp. 767$770,2005$.

[85] B. Mavis and A. C. Taş, "Dip coating of calcium hydroxyapatite on Ti-6Al-4V substrates," Journal of the American Ceramic Society, vol. 83, no. 4, pp. 989-991, 2000.

[86] S.-L. Chen, M.-H. Lin, G.-X. Huang, and C.-C. Wang, "Research of the recast layer on implant surface modified by micro-current electrical discharge machining using deionized water mixed with titanium powder as dielectric solvent," Applied Surface Science, vol. 311, pp. 47-53, 2014.

[87] B. E. J. Lee, S. Ho, G. Mestres, M. Karlsson Ott, P. Koshy, and K. Grandfield, "Dual-topography electrical discharge machining of titanium to improve biocompatibility," Surface and Coatings Technology, vol. 296, pp. 149-156, 2016.

[88] H. Marashi, A. A. D. Sarhan, and M. Hamdi, "Employing Ti nano-powder dielectric to enhance surface characteristics in electrical discharge machining of AISI D2 steel," Applied Surface Science, vol. 357, pp. 892-907, 2015.

[89] N. Ekmekci and B. Ekmekci, "Electrical Discharge Machining of Ti6Al4V in Hydroxyapatite Powder Mixed Dielectric Liquid," Materials and Manufacturing Processes, vol. 31, no. 13, pp. 16631670, 2016.

[90] N. Ekmekci and B. Ekmekci, "Hydroxyapatite deposition onto Ti-6Al-4V surface in powder mixed electrical discharge machining," Advanced Materials Research, vol. 856, pp. 205209, 2014.

[91] S.-L. Chen, M.-H. Lin, C.-C. Chen, and K.-L. Ou, "Effect of electro-discharging on formation of biocompatible layer on implant surface," Journal of Alloys and Compounds, vol. 456, no. 1-2, pp. 413-418, 2008.

[92] P. Janmanee and A. Muttamara, "Surface modification of tungsten carbide by electrical discharge coating (EDC) using a titanium powder suspension," Applied Surface Science, vol. 258, no. 19, pp. 7255-7265, 2012.

[93] C. Eriksson, J. Lausmaa, and H. Nygren, "Interactions between human whole blood and modified $\mathrm{TiO}_{2}$-surfaces: Influence of surface topography and oxide thickness on leukocyte adhesion and activation," Biomaterials, vol. 22, no. 14, pp. 1987-1996, 2001.

[94] S. B. Goodman, Z. Yao, M. Keeney, and F. Yang, "The future of biologic coatings for orthopaedic implants," Biomaterials, vol. 34, no. 13, pp. 3174-3183, 2013. 
[95] W. Habraken, P. Habibovic, M. Epple, and M. Bohner, "Calcium phosphates in biomedical applications: Materials for the future?" Materials Today, vol. 19, no. 2, pp. 69-87, 2016.

[96] M. H. Fathi and F. Azam, "Novel hydroxyapatite/tantalum surface coating for metallic dental implant," Materials Letters, vol. 61, no. 4-5, pp. 1238-1241, 2007.

[97] Y. Wang, H. Yu, C. Chen, and Z. Zhao, "Review of the biocompatibility of micro-arc oxidation coated titanium alloys," Materials and Design, vol. 85, pp. 640-652, 2015.

[98] R. A. Surmenev, M. A. Surmeneva, and A. A. Ivanova, "Significance of calcium phosphate coatings for the enhancement of new bone osteogenesis - A review," Acta Biomaterialia, vol. 10, no. 2, pp. 557-579, 2014.

[99] B. M. Schumacher, R. Krampitz, and J.-P. Kruth, "Historical phases of EDM development driven by the dual influence of "Market Pull" and "Science Push", Procedia CIRP, vol. 6, pp. 5-12, 2013.

[100] G. Kibria, B. Pradhan, and B. Bhattacharyya, "Experimentation and analysis into micro-hole machining in EDM on Ti-6Al$4 \mathrm{~V}$ alloy using boron carbide powder mixed de-ionized water," International Journal of Materials, Manufacturing and Design, Academic Research Journals, pp. 17-35, 2012.

[101] J. W. Murray, J. Sun, D. V. Patil, T. A. Wood, and A. T. Clare, "Physical and electrical characteristics of EDM debris," Journal of Materials Processing Technology, vol. 229, pp. 54-60, 2016.

[102] T. Muthuramalingam and B. Mohan, "A review on influence of electrical process parameters in EDM process," Archives of Civil and Mechanical Engineering, vol. 15, no. 1, pp. 87-94, 2015.

[103] N. Mohd Abbas, D. G. Solomon, and M. Fuad Bahari, "A review on current research trends in electrical discharge machining (EDM)," International Journal of Machine Tools and Manufacture, vol. 47, no. 7-8, pp. 1214-1228, 2007.

[104] A. Al-Khazraji, S. A. Amin, and S. M. Ali, "The effect of $\mathrm{SiC}$ powder mixing electrical discharge machining on white layer thickness, heat flux and fatigue life of AISI D2 die steel," Engineering Science and Technology, an International Journal, vol. 19, no. 3, pp. 1400-1415, 2016.

[105] S. S. Habib, "Study of the parameters in electrical discharge machining through response surface methodology approach," Applied Mathematical Modelling, vol. 33, no. 12, pp. 4397-4407, 2009.

[106] M. Durairaj, D. Sudharsun, and N. Swamynathan, "Analysis of process parameters in wire EDM with stainless steel using single objective Taguchi method and multi objective grey relational grade," Procedia Engineering, vol. 64, pp. 868-877, 2013.

[107] H. Dong, Y. Liu, Y. Shen, and X. Wang, "Optimizing Machining Parameters of Compound Machining of Inconel718," Procedia CIRP, vol. 42, pp. 51-56, 2016.

[108] G. Kibria, B. R. Sarkar, B. B. Pradhan, and B. Bhattacharyya, "Comparative study of different dielectrics for micro-EDM performance during microhole machining of Ti-6Al-4V alloy," The International Journal of Advanced Manufacturing Technology, vol. 48, no. 5-8, pp. 557-570, 2010.

[109] G. Ugrasen, H. V. Ravindra, G. V. Naveen Prakash, and Y. N. Theertha Prasad, "Optimization of Process Parameters in Wire EDM of HCHCr Material Using Taguchi's Technique," Materials Today: Proceedings, vol. 2, no. 4-5, pp. 2443-2452, 2015.

[110] W. König, D. F. Dauw, G. Levy, and U. Panten, "EDMfuture steps towards the machining of ceramics," CIRP Annals-Manufacturing Technology, vol. 37, no. 2, pp. 623-631, 1988.
[111] A. A. A. Aliyu, J. M. Rohani, A. M. A. Rani, and H. Musa, "Optimization of electrical discharge machining parameters of SiSiC through response surface methodology," Jurnal Teknologi, vol. 79, no. 1, pp. 119-129, 2017.

[112] S. L. Chen, B. H. Yan, and F. Y. Huang, "Influence of kerosene and distilled water as dielectrics on the electric discharge machining characteristics of Ti-6A1-4V,' Journal of Materials Processing Technology, vol. 87, no. 1-3, pp. 107-111, 1999.

[113] F. N. Leão and I. R. Pashby, "A review on the use of environmentally-friendly dielectric fluids in electrical discharge machining," Journal of Materials Processing Technology, vol. 149, no. 1-3, pp. 341-346, 2004.

[114] Z. Yu, T. Jun, and K. Masanori, "Dry electrical discharge machining of cemented carbide," Journal of Materials Processing Technology, vol. 149, no. 1-3, pp. 353-357, 2004.

[115] C. C. Kao, J. Tao, and A. J. Shih, "Near dry electrical discharge machining," International Journal of Machine Tools and Manufacture, vol. 47, no. 15, pp. 2273-2281, 2007.

[116] J. Tao, A. J. Shih, and J. Ni, "Experimental study of the dry and near-dry electrical discharge milling processes," Journal of Manufacturing Science and Engineering, Transactions of the ASME, vol. 130, no. 1, pp. 0110021-0110029, 2008.

[117] J. Tao, A. J. Shih, and J. Ni, "Near-dry EDM milling of mirrorlike surface finish," International Journal of Electrical Machining, vol. 13, no. 1, pp. 29-33, 2008.

[118] S. K. Saha and S. K. Choudhury, "Experimental investigation and empirical modeling of the dry electric discharge machining process," International Journal of Machine Tools and Manufacture, vol. 49, no. 3-4, pp. 297-308, 2009.

[119] P. S. Gajjar, H. P. Bhavsar, D. V. Modi, and B. D. Kayasth, "A review on parametric analysis of dry electric discharge machining," International Journal of Engineering Innovation and Scientific Research, vol. 1, no. 1, 2015.

[120] Y. Shen, Y. Liu, and W. Sun, "High-efficient Dry Hybrid Machining of EDM and Arc Machining," Procedia CIRP, vol. 42, pp. 149-154, 2016.

[121] W. Konig, F. Klocke, and M. Sparrer, "EDM-sinking using water-based dielectrics and electropolishing-a new manufacturing sequence in tool-making," in Proceedings of the in Proceedings of the 11th International Symposium on Electromachining (ISEM XI), Lausanne, Switzerland, 1995.

[122] K. Furutani, N. Mohri, N. Saito, H. Takezawa, H. Takezawa, and M. Higashi, "Simultaneous finishing a pair of dies by electrical discharge grinding," in Rapid Product Development, pp. 263272, Chapman \& Hall, in association with Japan Society for Precision Engineering, London, UK, 1997.

[123] M. Kunieda, M. Yoshida, and N. Taniguchi, "Electrical discharge machining in gas," CIRP Annals - Manufacturing Technology, vol. 46, no. 1, pp. 143-146, 1997.

[124] B. H. Yan, Y. C. Lin, F. Y. Huang, and C. H. Wang, "Surface modification of SKD 61 during EDM with metal powder in the dielectric," Materials Transactions, vol. 42, no. 12, pp. 25972604, 2001.

[125] Z. L. Wang, Y. Fang, P. N. Wu, W. S. Zhao, and K. Cheng, "Surface modification process by electrical discharge machining with a Ti powder green compact electrode," Journal of Materials Processing Technology, vol. 129, no. 1-3, pp. 139-142, 2002.

[126] J. Simao, H. G. Lee, D. K. Aspinwall, R. C. Dewes, and E. M. Aspinwall, "Workpiece surface modification using electrical discharge machining," International Journal of Machine Tools and Manufacture, vol. 43, no. 2, pp. 121-128, 2003. 
[127] H. S. Lim, Y. S. Wong, M. Rahman, and M. K. Edwin Lee, "A study on the machining of high-aspect ratio micro-structures using micro-EDM," Journal of Materials Processing Technology, vol. 140, no. 1-3, pp. 318-325, 2003.

[128] E. Uhlmann, S. Piltz, and U. Doll, "Machining of micro/miniature dies and moulds by electrical discharge machining - Recent development," Journal of Materials Processing Technology, vol. 167, no. 2-3, pp. 488-493, 2005.

[129] E. Uhlmann, S. Piltz, and D. Oberschmidt, "Machining of micro rotational parts by wire electrical discharge grinding," Production Engineering, vol. 2, no. 3, pp. 227-233, 2008.

[130] P. Govindan, A. Gupta, S. S. Joshi, A. Malshe, and K. P. Rajurkar, "Single-spark analysis of removal phenomenon in magnetic field assisted dry EDM," Journal of Materials Processing Technology, vol. 213, no. 7, pp. 1048-1058, 2013.

[131] S. Joshi, P. Govindan, A. Malshe, and K. Rajurkar, "Experimental characterization of dry EDM performed in a pulsating magnetic field," CIRP Annals - Manufacturing Technology, vol. 60, no. 1, pp. 239-242, 2011.

[132] I. Ayesta, B. Izquierdo, J. A. Sánchez et al., "Influence of EDM parameters on slot machining in C1023 aeronautical alloy," Procedia CIRP, vol. 6, pp. 129-134, 2013.

[133] E. Uhlmann and D. C. Domingos, "Investigations on vibrationassisted EDM-machining of seal slots in high-temperature resistant materials for turbine components," Procedia CIRP, vol. 6, pp. 71-76, 2013.

[134] E. Uhlmann and D. C. Domingos, "Investigations on Vibrationassisted EDM-machining of Seal Slots in High-Temperature Resistant Materials for Turbine Components -Part II," Procedia CIRP, vol. 42, pp. 334-339, 2016.

[135] U. S. Yadav and V. Yadava, "Experimental modeling and multiobjective optimization of electrical discharge drilling of aerospace superalloy material," Proceedings of the Institution of Mechanical Engineers, Part B: Journal of Engineering Manufacture, vol. 229, no. 10, pp. 1764-1780, 2015.

[136] W. F. Sales, A. R. F. Oliveira, and A. A. Raslan, "Titanium perovskite (CaTiO3) formation in Ti6Al4V alloy using the electrical discharge machining process for biomedical applications," Surface and Coatings Technology, vol. 307, pp. 1011-1015, 2016.

[137] M. Shabgard and B. Khosrozadeh, "Investigation of carbon nanotube added dielectric on the surface characteristics and machining performance of Ti-6Al-4V alloy in EDM process," Journal of Manufacturing Processes, vol. 25, pp. 212-219, 2017.

[138] P. Peças and E. Henriques, "Electrical discharge machining using simple and powder-mixed dielectric: The effect of the electrode area in the surface roughness and topography," Journal of Materials Processing Technology, vol. 200, no. 1-3, pp. 250258, 2008.

[139] W. Rehbein, H.-P. Schulze, K. Mecke, G. Wollenberg, and M. Storr, "Influence of selected groups of additives on breakdown in EDM sinking," Journal of Materials Processing Technology, vol. 149, no. 1-3, pp. 58-64, 2004.

[140] S. K. Choudhary and R. Jadoun, "Current Research development in Dry Electric Discharge Machining (DEDM): Review Paper," International Journal of Emerging Technology and Advanced Engineering, vol. 4, no. 8, pp. 832-839, 2014.

[141] Y.-F. Tzeng and C.-Y. Lee, "Effects of powder characteristics on electrodischarge machining efficiency," International Journal of Advanced Manufacturing Technology, vol. 17, no. 8, pp. 586-592, 2001.
[142] R. Toshimitsu, A. Okada, R. Kitada, and Y. Okamoto, "Improvement in Surface Characteristics by EDM with Chromium Powder Mixed Fluid," Procedia CIRP, vol. 42, pp. 231-235, 2016.

[143] B. Singh, J. Kumar, and S. Kumar, "Influences of Process Parameters on MRR Improvement in Simple and PowderMixed EDM of AA6061/10\%SiC Composite," Materials and Manufacturing Processes, vol. 30, no. 3, pp. 303-312, 2015.

[144] R. Bajaj, A. K. Tiwari, and A. R. Dixit, "Current Trends in Electric Discharge Machining Using Micro and Nano Powder Materials- A Review," Materials Today: Proceedings, vol. 2, no. 4-5, pp. 3302-3307, 2015.

[145] M. Kolli and A. Kumar, "Effect of dielectric fluid with surfactant and graphite powder on Electrical Discharge Machining of titanium alloy using Taguchi method," Engineering Science and Technology, an International Journal, vol. 18, no. 4, pp. 524-535, 2015.

[146] B. H. Yan, H. C. Tsai, and F. Y. Huang, "The effect in EDM of a dielectric of a urea solution in water on modifying the surface of titanium," International Journal of Machine Tools and Manufacture, vol. 45, no. 2, pp. 194-200, 2005.

[147] L. Liqing and S. Yingjie, "Study of dry EDM with oxygen-mixed and cryogenic cooling approaches," Procedia CIRP, vol. 6, pp. 344-350, 2013.

[148] K. Dhakar and A. Dvivedi, "Parametric Evaluation on Near-Dry Electric Discharge Machining," Materials and Manufacturing Processes, vol. 31, no. 4, pp. 413-421, 2016.

[149] T.-S. Huang, S.-F. Hsieh, S.-L. Chen, M.-H. Lin, S.-F. Ou, and W.-T. Chang, "Surface modification of TiNi-based shape memory alloys by dry electrical discharge machining," Journal of Materials Processing Technology, vol. 221, pp. 279-284, 2015.

[150] O. Gülcan, İ. Uslan, Y. Usta, and C. Çoğun, "Performance and surface alloying characteristics of $\mathrm{Cu}-\mathrm{Cr}$ and $\mathrm{Cu}-\mathrm{Mo}$ powder metal tool electrodes in electrical discharge machining," Machining Science and Technology, vol. 20, no. 4, pp. 523-546, 2016.

[151] J.-P. Kruth, L. Stevens, L. Froyen, and B. Lauwers, "Study of the White Layer of a Surface Machined by Die-Sinking Electro-Discharge Machining," CIRP Annals - Manufacturing Technology, vol. 44, no. 1, pp. 169-172, 1995.

[152] A. Kumar, V. Kumar, and J. Kumar, "Surface crack density and recast layer thickness analysis in WEDM process through response surface methodology," Machining Science and Technology, vol. 20, no. 2, pp. 201-230, 2016.

[153] Y. Zhang, Y. Liu, R. Ji, and B. Cai, "Study of the recast layer of a surface machined by sinking electrical discharge machining using water-in-oil emulsion as dielectric," Applied Surface Science, vol. 257, no. 14, pp. 5989-5997, 2011.

[154] Y. Zhang, Y. Liu, R. Ji, B. Cai, and H. Li, "Influence of dielectric type on porosity formation on electrical discharge machined surfaces," Metallurgical and Materials Transactions B: Process Metallurgy and Materials Processing Science, vol. 43, no. 4, pp. 946-953, 2012.

[155] W. Cao and L. L. Hench, "Bioactive materials," Ceramics International, vol. 22, no. 6, pp. 493-507, 1996.

[156] T. Kokubo, H. Kim, and M. Kawashita, "Novel bioactive materials with different mechanical properties," Biomaterials, vol. 24, no. 13, pp. 2161-2175, 2003.

[157] J. Strasky, M. Janecek, and P. Harcuba, "Electric discharge machining of Ti-6Al-4V alloy for Biomedical Use," in Proceedings of Contributed Papers, Part III (WDS' 11), pp. 127-131, 2011. 
[158] T.-S. Yang, M.-S. Huang, M.-S. Wang, M.-H. Lin, M.-Y. Tsai, and P.-Y. Wang Wang, "Effect of electrical discharging on formation of nanoporous biocompatible layer on Ti-6Al-4V alloys," Implant Dentistry, vol. 22, no. 4, pp. 374-379, 2013.

[159] F. Otsuka, Y. Kataoka, and T. Miyazaki, "Enhanced osteoblast response to electrical discharge machining surface," Dental Materials Journal, vol. 31, no. 2, pp. 309-315, 2012.

[160] C. Prakash, H. K. Kansal, B. S. Pabla, and S. Puri, "Processing and Characterization of Novel Biomimetic Nanoporous Bioceramic Surface on $\beta$-Ti Implant by Powder Mixed Electric Discharge Machining," Journal of Materials Engineering and Performance, vol. 24, no. 9, pp. 3622-3633, 2015.

[161] C. Prakash, H. K. Kansal, B. S. Pabla, and S. Puri, "Effect of surface nano-porosities fabricated by powder mixed electric discharge machining on bone-implant interface: An experimental and finite element study," Nanoscience and Nanotechnology Letters, vol. 8, no. 10, pp. 815-826, 2016.

[162] C. Prakash, H. Kansal, B. Pabla, and S. Puri, "On the Influence of Nanoporous Layer Fabricated by PMEDM on $\beta$-Ti Implant: Biological and Computational Evaluation of Bone- Implant Interface," in Proceedings of the 5th International Conference of Materials Processing and Characterization, Hyderabad, India, 2016.

[163] C. Prakash, H. K. Kansal, B. S. Pabla, and S. Puri, "Powder Mixed Electric Discharge Machining: An Innovative Surface Modification Technique to Enhance Fatigue Performance and Bioactivity of $\beta$-Ti Implant for Orthopedics Application," Journal of Computing and Information Science in Engineering, vol. 16, no. 4, Article ID 041006, 2016.

[164] S. J. Algodi, J. W. Murray, M. W. Fay, A. T. Clare, and P. D. Brown, "Electrical discharge coating of nanostructured TiC-Fe cermets on 304 stainless steel," Surface and Coatings Technology, vol. 307, pp. 639-649, 2016.

[165] C. Prakash, H. K. Kansal, B. Pabla, and S. Puri, "Potential of Silicon Powder-Mixed Electro Spark Alloying for Surface Modification of $\beta$-Phase Titanium Alloy for Orthopedic Applications," in Proceedings of the International Conference on Recent Trends in Engineering and Material Sciences (ICEMS-2016), Jaipur, India, March 2016.

[166] Z. J. Xie, Y. J. Mai, W. Q. Lian, S. L. He, and X. H. Jie, “Titanium carbide coating with enhanced tribological properties obtained by EDC using partially sintered titanium electrodes and graphite powder mixed dielectric," Surface and Coatings Technology, vol. 300, pp. 50-57, 2016.

[167] L. Li, L. Zhao, Z. Y. Li, L. Feng, and X. Bai, "Surface characteristics of Ti-6Al-4V by SiC abrasive-mixed EDM with magnetic stirring," Materials and Manufacturing Processes, vol. 32, no. 1, pp. 83-86, 2017.

[168] B. Kuriachen and J. Mathew, "Effect of Powder Mixed Dielectric on Material Removal and Surface Modification in Microelectric Discharge Machining of Ti-6Al-4V,' Materials and Manufacturing Processes, vol. 31, no. 4, pp. 439-446, 2016. 

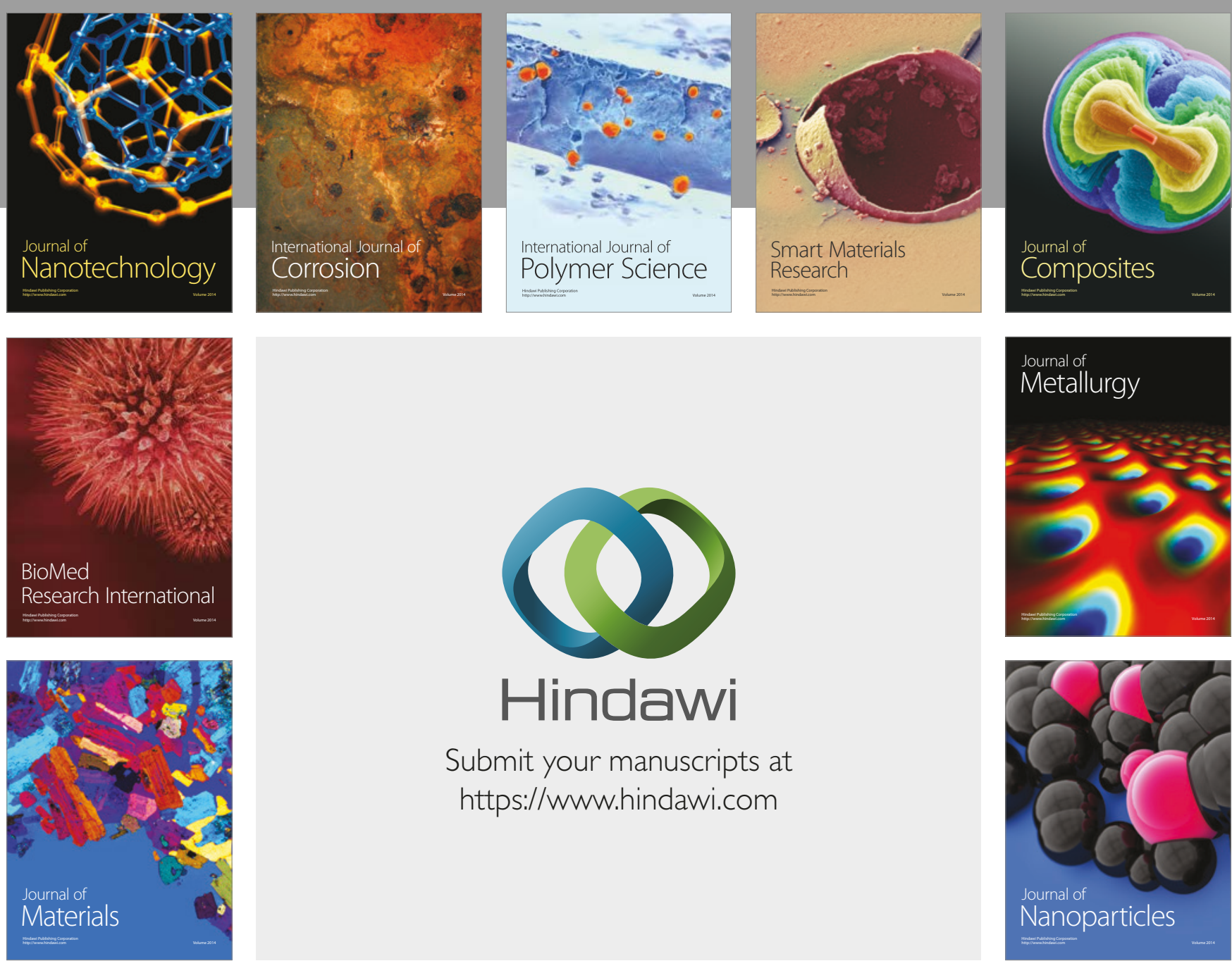

\section{Hindawi}

Submit your manuscripts at

https://www.hindawi.com
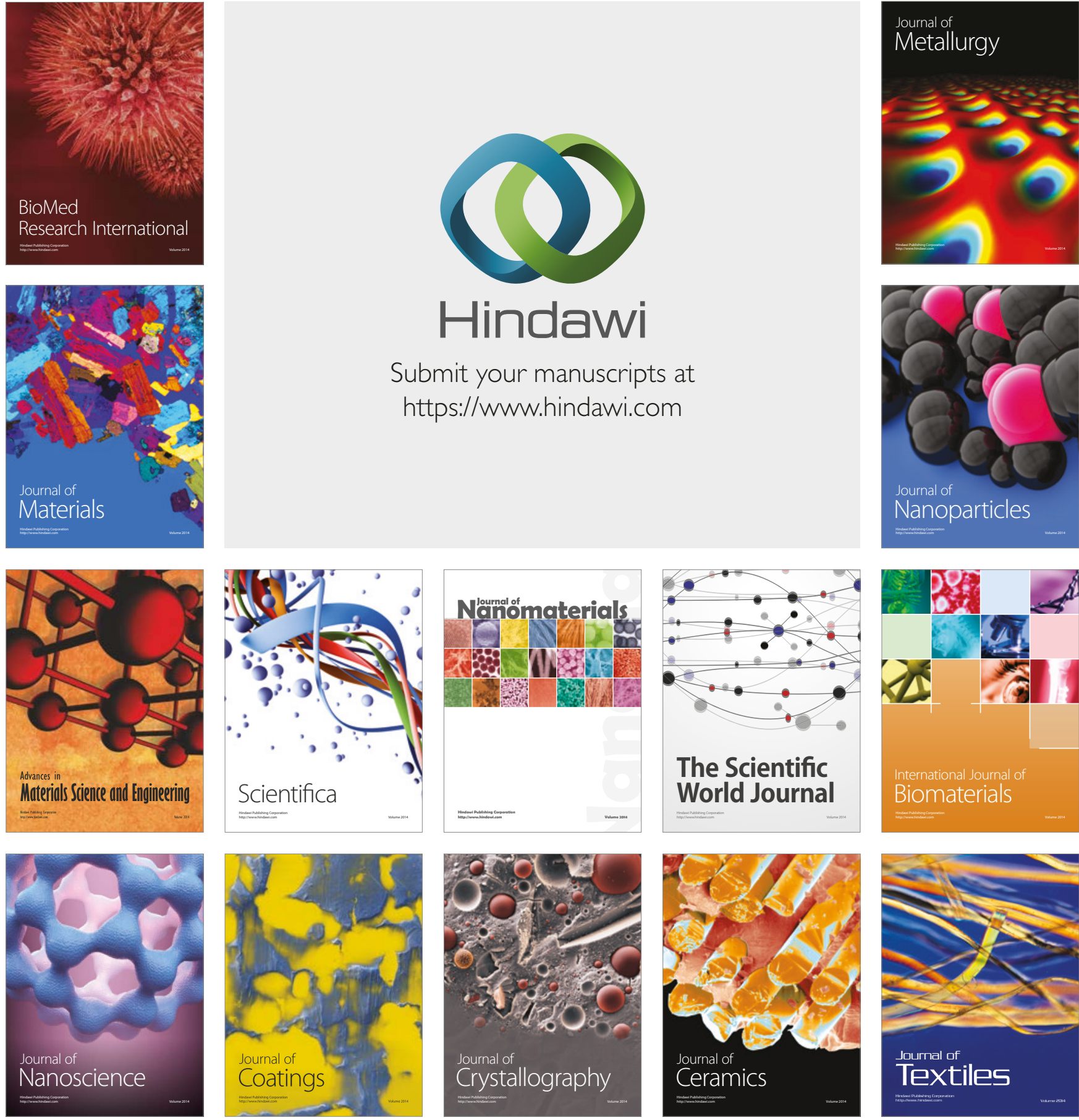

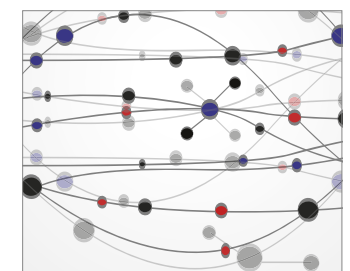

The Scientific World Journal
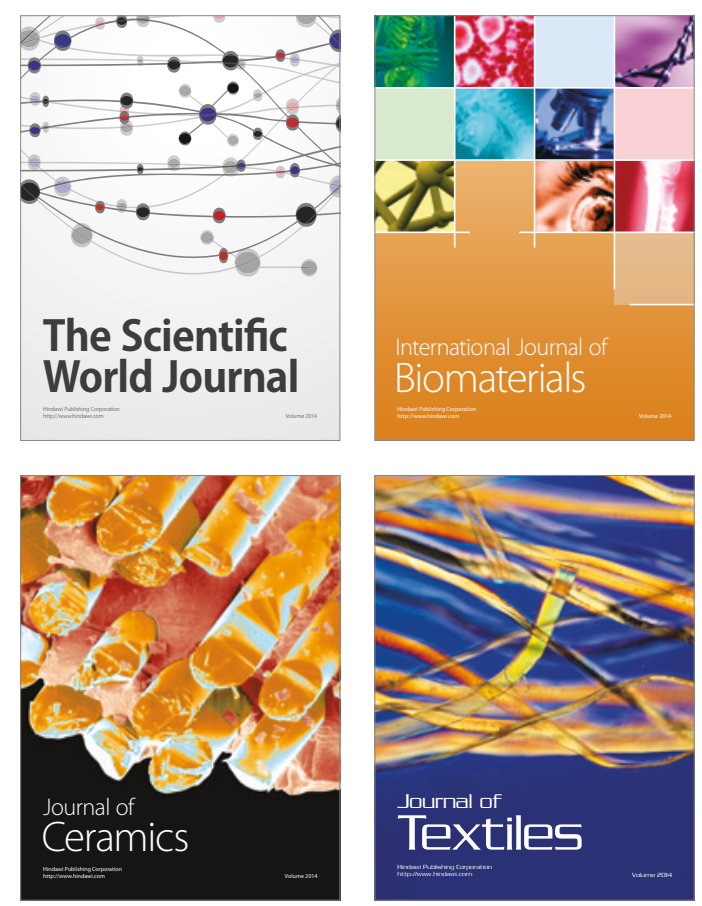